\title{
Mujeres en Yucatán: Nuevas figuras obreras a partir del modelo maquilador extranjero
}

\author{
Beatriz Castilla R. Y Beatriz Torres G. ${ }^{1}$ \\ Unidad de Ciencias Sociales. \\ Centro de Investigaciones Regionales "Dr. Hideyo Noguchi" \\ Universidad Autónoma de Yucatán. Mérida. México
}

\section{INTRODUCCIÓN}

México, por su posición geográfica estratégica y disponibilidad de recursos humanos, se convirtió desde hace tres décadas, a través de su programa de maquiladoras, en un país idóneo para los proyectos de subcontratación de empresas de EE.UU. y, en la década de los ochenta, comenzó a observarse la presencia de capitales asiáticos, especialmente el japonés (Opalín 1995).

Para el gobierno mexicano este tipo de inversión constituyó en un principio un paliativo al problema regional de desempleo en la Frontera Norte. No obstante, desde mediados de los ochenta, la industria maquiladora se transformó en un importante vector para la obtención de divisas y la absorción del empleo a escala nacional (Hualde y Mercado 1996). El desarrollo y consolidación de la industria maquiladora de exportación ha permitido que ésta se convierta hoy día, junto con el petróleo y el turismo, en la fuente más importante de divisas para el país, así como en un creador dinámico de empleos, que inicialmente se concentraban en los estados fronterizos y desde hace algunos años en otras regiones de la República Mexicana.

Es de interés señalar que en el contexto de las transformaciones actuales de la situación económica internacional, se han creado nuevas condiciones de competencia en el mercado mundial que han impreso un nuevo giro a la industria maquiladora, a través de una mayor diversificación de fases productivas que demandan mayores niveles tecnológicos y que rebasan los procesos únicamente de ensamble. Este hecho está dando lugar a la presencia de industrias manufactureras en cuyo seno se elabora el proceso global de producción; hecho que ha traído aparejadas

1 Agradecemos la valiosa colaboración de Mauricio Dzul y Luis Hernández, por el apoyo técnico que nos ofrecieron durante la elaboración de este trabajo. 
relevantes transformaciones en los perfiles ocupacionales, en donde destacan las nuevas figuras obreras de alta calificación técnica.

Carrillo y De la O (1991) señalan que a partir de los años ochenta empieza un proceso de modernización productiva en la industria maquiladora de exportación caracterizado por la incorporación de nuevas tecnologías, nuevas formas de organizar el trabajo, cambios en la gestión de recursos humanos y transformaciones en las relaciones contractuales. Hay consenso acerca de que este movimiento constituye una respuesta a las nuevas condiciones de competencia internacional (específicamente en cuanto al control y aplicación de tecnología flexible en países industrializados), de las prácticas corporativas comerciales, así como de las nuevas relaciones establecidas entre las matrices y las subsidiarias a partir del uso intensivo de tecnologías blandas. Elementos que, a decir de los autores, definen el futuro vínculo entre los procesos de reestructuración industrial, de internacionalización productiva y de competencia global (Ibid.). En este último punto, como señala Carrillo (1998), hay que poner el acento en que el fenómeno de exportación y competitividad que se observa recientemente en el país está íntimamente ligado a la transnacionalización de la economía.

Investigaciones recientes han documentado la evolución de la industria maquiladora de exportación hacia una nueva fase tecnológica y laboral. Dicho proceso se inscribe, en términos generales, en los cambios recientes en los patrones de competencia internacional en las industrias de punta: la competencia tiende a globalizarse cada vez más, enfrentando a las industrias entre sí a escala mundial y no en mercados específicos. Esta dinámica de competencia internacional implica una atención cada vez mayor hacia los niveles de calidad e innovación de los productos finales, de tal suerte que las empresas se ven obligadas a buscar un mayor control sobre los diferentes segmentos del proceso global, así como un mayor perfeccionamiento en los sistemas de control de calidad (Carrillo y Contreras 1992). En este contexto, las estrategias corporativas dejan de basarse de manera exclusiva en el costo salarial de la fuerza de trabajo como criterio de ventaja competitiva y desarrollan opciones sustentadas en el uso de tecnologías flexibles, así como en nuevos paradigmas de organización del trabajo (Ibid.), orientados a la búsqueda del consenso en la producción. Al respecto, hay que hacer hincapié en la heterogeneidad de este proceso aún en marcha y detenerse en los efectos que estas reestructuraciones están teniendo en los espacios regionales en donde operan las plantas maquiladoras, con el propósito de poner de relieve los cambios en la política laboral, así como en la calificación de los trabajadores. Sin dejar por eso de mencionar la existencia de empresas que 
desarrollan poco sus recursos humanos, operan con bajos niveles tecnológicos y cuya rentabilidad estriba en la intensidad del trabajo vivo y los bajos salarios.

Para situar la relevancia de la industria maquiladora en el país basta señalar que a poco más de treinta años de haberse instalado doce fábricas y generado en aquel entonces tres mil empleos, actualmente esta industria cuenta con alrededor de 4.000 instalaciones y un millón de empleos directos, representando su producción el cincuenta por ciento de las ventas del sector manufacturero en el exterior. Los datos anteriores nos ponen de manifiesto que pese a la difícil situación económica que atraviesa México, se continúan realizando importantes inversiones extranjeras. Así, según la Secretaría de Comercio y Fomento Industrial (SECOFI), en el primer semestre de 1998, la inversión extranjera canalizada al rubro de maquiladoras llegó a 543.62 millones de dólares, recursos destinados tanto a la creación de nuevas plantas como a la ampliación de otras ya existentes.

En este escenario, la industria maquiladora de exportación en Yucatán se presenta como un indicio del proceso de globalización de la economía del Estado. La presencia de estas factorías transforma la fisonomía del sector industrial al incorporar nuevas ramas y nuevas formas de organizar el trabajo, caracterizadas por un nuevo estilo de gestión de la fuerza de trabajo y por la emergencia de nuevas figuras obreras, en esencia femeninas.

EL CONTEXTO SOCIOTERRITORIAL COMO SEDE DEL PROYECTO MAQUILADOR Y CONFIGURADOR DE NUEVAS FIGURAS LABORALES ${ }^{2}$

El estado de Yucatán, localizado en la península del mismo nombre, al sur del territorio mexicano, se inicia en la industria en 1850 con la mecanización de la raspa del henequén (agave foucroydes), planta nativa de la región, que durante la época prehispánica los indígenas mayas cultivaban para su autoconsumo, con una lógica de intercambio con la naturaleza ${ }^{3}$ y con métodos rudimentarios. Las necesidades de la agricultura norteamericana imprimieron otro sentido: el de la producción a gran escala, ya que las engavilladoras-atadoras de cereales utilizadas en el país vecino demandaban cordel de henequén para su funcionamiento. Los hacendados yucatecos respondieron a esta demanda, primero mecanizan-

2 Ver sobre este tema en concreto Torres (en proceso).

3 Al respecto, véase el excelente trabajo de García Quintanilla (1999). 
do el desfibrado con algunos inventos de los industriales locales ${ }^{4} \mathrm{y}$, después, con la introducción de máquinas de vapor (1861) a fin de alcanzar la producción a gran escala. De esta manera, la actividad de las casas de máquinas ubicadas en las haciendas henequeneras aumenta frenéticamente, con el propósito de transformar las espinosas pencas del henequén en codiciadas sogas y cordeles, así como de otros derivados del sosquil para su exportación.

Así, entre 1880-1918, etapa conocida en la historia yucateca como del auge henequenero, el valor de las pacas producidas se incrementa de un millón 778 mil pesos en el año de 1880, a 91 millones de pesos en 1918 (Ramírez 1997). Con el fin de refaccionar esta actividad surgen pequeños talleres de forja y laminado que junto con la existencia de algunas cordelerías encargadas de transformar la fibra en cordeles y sacos y la elaboración de bienes de consumo básicos, vienen a gestar el sector industrial en la región sureste del país. A fines del siglo xix e inicios del $\mathrm{xx}$, surgen plantas de hielo, fábricas de chocolates, de cerillas, ingenios azucareros, sombrererías y alfarerías. Al respecto, cabe señalar, que dentro de esta industria local, productora de bienes de consumo inmediato, predominaban los establecimientos familiares de alimentos y bebidas (cerveza, refrescos, panaderías, tabaco) orientados al mercado interno. El poco desarrollo de la industria, observado en esa época, obedece a que los capitales de la región estaban canalizados mayoritariamente hacia la actividad henequenera y a lo poco atractivo que resultaba el mercado interno para los empresarios del ramo, dado el paupérrimo poder adquisitivo de los habitantes del mayab; si recordamos que en esa época imperaba el sistema hacendario de amos y sirvientes. En este régimen, la mayor parte de la población yucateca vivía en las haciendas, cuyos bienes de consumo básico eran provistos en las tiendas de raya, mientras que los hacendados henequeneros se surtían de exclusivos bienes de consumo y objetos suntuarios en el extranjero.

La ya mencionada concentración del capital yucateco en la monoproducción henequenera para exportación convirtió a Yucatán en uno de los estados más ricos del país, al mismo tiempo que inhibió el desarrollo de otros sectores económicos. Hasta después de la Revolución, la industria local no muestra un relativo crecimiento, debido al desarrollo de un mercado interno demandante de bienes de consumo inmediato, tras la desaparición del sistema de producción hacendario que acabó con el peonaje, la servidumbre y las tiendas de raya en las haciendas.

${ }^{4}$ Nos referimos a la rueda Solis con capacidad de desfibrar 1.000 pencas por hora y la rueda vencedora que desfibrara 20.000 por hora. 
Con la creación de Cordemex, organismo paraestatal para regular la actividad henequenera en 1964, las cordelerías privadas son adquiridas por el Estado, hecho que marcó el inicio de la diversificación económica de la región ya que las indemnizaciones que recibieron los empresarios cordeleros por sus plantas constituyeron el capital inicial para introducirse en otras actividades productivas.

A partir de los años setenta, y durante poco más de una década, hasta llegar al colapso financiero de 1982, se considera la segunda etapa de industrialización en Yucatán. En ésta, la ampliación del mercado local, el desarrollo de las actividades comerciales y de servicios, el crecimiento demográfico de la ciudad de Mérida, el nacimiento de Cancún como polo turístico, que demandaba bienes diversos por su acelerado crecimiento, así como el auge petrolero en Tabasco, al norte de Chiapas y en la sonda de Campeche, se convierten en factores que estimularon una creciente demanda de bienes y servicios, que se apresuraron a satisfacer las empresas locales, entre las que destacan las de alimentos y bebidas por el número de empleos que generaron.

A inicios de la década de los ochenta comienzan a llegar capitales nacionales y transnacionales de empresas manufactureras, de comercio y de servicios que antes no existían en la región. Algunas de las manufactureras foráneas adquirieron empresas locales, mientras que otras llegaron directamente a instalarse en la zona. La crisis económica nacional de 1982 dañó definitivamente la ya mermada industria henequenera, que había concentrado su poder en la paraestatal Cordemex ${ }^{5}$, cuya producción se derrumbó y ocasionó el cierre de esta gigantesca empresa en un lento proceso de liquidación de los subsidios a los campesinos henequeneros que concluyó en 1992, y dejó sin empleo a más de 200.000 trabajadores. El sector primario requirió entonces ser reorientado hacia otros cultivos y principalmente hacia la ganadería (porcicultura y avicultura), actividades en las que hoy se sustenta en el Estado la importante y creciente industria de la carne.

En 1985 como consecuencia de los puntos centrales del Programa Gubernamental de Reordenación Henequenera y Desarrollo Integral de Yucatán aparecen las primeras maquiladoras de capital extranjero en Yucatán. En ese momento, dicho programa proclamaba entre sus objetivos principales el de cubrir el déficit de empleo provocado por la deca-

5 El "problema henequenero", marcó una lenta agonía de una industria que llegó a ser el pilar de la economía de Yucatán e hizo de la entidad una de las más ricas de México. En la actualidad, permanecen funcionando algunas cordelerías y empresas relacionadas con el henequén, pero sin la fuerza que llegó a acumular Cordemex. 
dencia de las actividades económicas vinculadas a la producción henequenera. Una década después, pese a las fluctuaciones y tropiezos que ha tenido que enfrentar esta industria, se puede afirmar que el sector maquilador de exportación se ha estado consolidando como uno de los más importantes y dinámicos de la economía yucateca, cuyo crecimiento en el empleo es actualmente el más alto en el país (Castilla y Torres 1994).

La relevancia de esta industria en la zona es tal que constituye la segunda actividad económica en cuanto a la captación de divisas, sólo superada por el turismo. Según declaraciones recientes del presidente de la Asociación de Maquiladoras de Yucatán A. C., Jess Dalton, el Estado figura ya como uno de los destinos internacionales para invertir en maquiladoras de géneros como ropa, joyería, artículos de ortodoncia, electrónicos, deportivos y metal-mecánica, por lo que actualmente debe estimularse la presencia de empresas de segunda generación.

\section{PRESENCIA DE LA INDUSTRIA MAQUILADORA EN YUCATÁN}

La instalación de plantas día a día nos toma por sorpresa ¿cuál es la explicación? Además de los bajos salarios (un dólar hora/hombre, incluyendo prestaciones e incentivos), la abundancia de mano de obra arraigada a la tierra y la rentabilidad de los costos de operación apuntalada en las bondades de la infraestructura, se cuenta con un atractivo más sólido: la alta calidad de la mano de obra que, para orgullo nuestro, ha sido legitimada en los mercados de cuatro continentes: América, Europa, Asia y Oceanía (Castilla 2000) (ver anexo 2).

Actualmente el sector maquilador yucateco está conformado por 101 empresas maquiladoras $100 \%$ exportadoras, cuya mayoría se dedica a la fabricación de prendas de vestir, seguidas por las de joyería, transformadores eléctricos, procesado de alimentos y otras de productos diversos (gráfica 1).

La instalación de estas fábricas en el Estado se ha venido acentuando a partir de la firma del Tratado de Libre Comercio con EE.UU. y Canadá en enero de 1994, así como por el impacto de la política estatal de combatir el desempleo en el campo, mediante la instalación de plantas maquiladoras en ciudades del interior del Estado. El fenómeno de la desconcentración de la zona metropolitana de Mérida como sede de la industria maquiladora, y su consecuente desplazamiento a poblaciones de la zona maya yucateca, constituye un proyecto reciente para frenar la migración campo-ciudad, en determinadas áreas a partir de la caída del modelo henequenero. Hoy día podemos observar la operación de estas 
plantas en Motul, Izamal, Valladolid, Seyé, Tekax, Baca, Tekantó, Cholul, Conkal, Acanceh, Halachó, Hunucmá, Ixil, Dzidzantun, Tekit, Dzitya, lo que, desde la óptica de algunos estudiosos del tema, es visto como que "pretenden cambiar el oro verde por el oro maquilador al ser sustituidas las haciendas henequeneras por las instalaciones fabriles" (Villamil 1997) (gráfica 2).

El dinamismo en el empleo generado por el sector maquilador recientemente se observa en la gráfica 3, poniéndose de realce la industria del vestido. Al respecto el investigador Jorge Carrillo (1998) señaló la tendencia del Estado hacia la llamada "Especialización Productiva" en esta rama. Esta situación se constata al observar el traslado de empresas de la Frontera Norte hacia Yucatán, en busca de ventajas comparativas. La gráfica 4 nos revela la composición del capital, destacando por su importancia las empresas norteamericanas. No obstante, es interesante observar la presencia de otros países que han realizado coinversiones; tanto de capitales nacionales con extranjeros, como entre capitales extranjeros, y resulta de gran relevancia destacar la tendencia actual de los capitales locales a invertir bajo este régimen.

Con respecto al tamaño de las empresas se observa que el $25.25 \%$ del total corresponde a las multinacionales extranjeras que se registraron como grandes (más de 401 empleados). Asimismo, salta a la vista el peso porcentual de las micros y pequeñas que en total suman un $56.56 \%$. Estas son empresas tanto de capital local, como de capital extranjero (gráfica 4.1). La información presentada en la gráfica 4.2 se refiere estrictamente a las empresas nacionales $100 \%$ exportadoras inscritas en este régimen, en donde se puede apreciar que sólo un 11\% de ellas corresponde a empresas grandes. Con esto se confirma que son las empresas multinacionales extranjeras las que representan las unidades productivas codificadas como grandes ${ }^{6}$. Una atención especial hemos prestado a las empresas de capacidad ociosa en donde predominan las textiles y otras industrias manufactureras (gráfica 5), situadas principalmente en Mérida, aunque también en otros municipios del Estado (gráfica 6). En la gráfica 7 se muestra el predominio casi en su totalidad de empresas yucatecas con contrato de maquila. La información de campo nos reveló que se trata de pequeños talleres de costura y que en casi su mayoría son empresas locales que solicitan permisos temporales para inscribirse en el régimen maquilador aprovechando la coyuntura del mercado.

Los principales destinos de los productos fabricados en Yucatán, vía maquiladoras, son: Estados Unidos, Canadá, Honk Kong, Japón, Australia,

Algunas de éstas rebasan los 1.500 empleados y aún más si se suman las aplicaciones de estas empresas en otros puntos (rurales) del Estado. 
Inglaterra, Italia, Alemania, Holanda, Suiza, España, Centroamérica, Cuba, Puerto Rico, Brasil y Colombia.

Para atraer a los inversionistas extranjeros, el Estado ha establecido - desde la creación del proyecto maquilador - una serie de incentivos entre los que destacan la modificación de la legislación para permitir la instalación de empresas con $100 \%$ de capital extranjero, la exención del pago de impuestos a las empresas registradas en el régimen maquilador, así como una importante inversión en infraestructura. Actualmente se cuenta con siete parques industriales situados en la ciudad de Mérida y en varias localidades del interior del Estado y un Puerto de Altura, ubicado a 25 kilómetros de Mérida, para el transporte de los productos al extranjero. Otros apoyos a los empresarios maquiladores son las bajas tarifas de energía eléctrica y, recientemente, la dotación de terrenos para aquellos inversionistas que decidan invertir en el campo yucateco. En lo que respecta a la mano de obra, el Gobierno del Estado ha creado, desde el inicio de la operación de las fábricas, un programa de capacitación permanente mediante un sistema de beca-salario a los trabajadores que deseen incorporarse a las plantas maquiladoras y por su parte, el sector empresarial, a través de la Asociación de Maquiladoras A. C., ha puesto en marcha un programa de formación para mandos medios calificados y con liderazgo, a fin de resolver el déficit del personal en este nivel laboral ${ }^{7}$.

\section{LAS PLANTAS MAQUILADORAS COMO FUENTE DE EMPLEO FEMENINO}

En Yucatán, la presencia de las mujeres en la actividad económica data de tiempos lejanos (Torres 1998). A lo largo de su historia económica se puede constatar este hecho, acorde a las actividades económicas predominantes. Esto es, la distribución sectorial y ocupacional de las mujeres ha variado, de acuerdo a los vaivenes de la economía que, a lo largo de los años, las concentra en el sector industrial, en el del comercio y en los servicios. Lo mismo sucede con las ocupaciones desempeñadas por las trabajadoras que van cambiando como efecto del desarrollo del capitalismo mismo, que las va diversificando y modernizando, tal como se puede apreciar en los cuadros siguientes.

7 Entrevista al entonces presidente de la Asociación de Maquiladoras de Yucatán, Fabio Atti por Martín Elizondo en Infomaquila, n. ${ }^{\circ}$, diciembre de 1998. Asociación de Maquiladoras de Yucatán A. C. 
DistribuCión DE LA POBLACIÓN ECONÓMICAMENTE ACTIVA POR SEXOS EN YUCATÁN

\begin{tabular}{|l|c|c|c|r|r|}
\hline AÑOS & TOTAL & HOMBRES & $\%$ & MUJERES & $\%$ \\
\hline 1985 & 114799 & 103,155 & 89.85 & 11,644 & 10.14 \\
1900 & 110698 & 102,164 & 92.29 & 8,534 & 7.70 \\
1910 & 126206 & 105,217 & 83.36 & 20,991 & 16.63 \\
1930 & 132168 & 124,351 & 94.08 & 7,817 & 5.91 \\
1940 & 134917 & 129,236 & 95.78 & 5,681 & 4.21 \\
1970 & 201630 & 176,447 & 87.51 & 25,183 & 12.48 \\
1980 & 367825 & 274,270 & 74.56 & 93,555 & 25.43 \\
1990 & 407337 & 320,515 & 78.68 & 86,822 & 21.31 \\
\hline
\end{tabular}

Actualización a 1990 de Torres (1987).

PaRticipación femenina en la ACtividad ECONómica de YuCatán

\begin{tabular}{|c|c|c|c|c|c|c|c|c|}
\hline ANOS & 1895 & 1900 & 1910 & 1930 & 1940 & 1970 & 1980 & 1990 \\
\hline Agricultura .......... & & $\begin{array}{c}16 \\
.18 \%\end{array}$ & $\begin{array}{l}146 \\
.69 \%\end{array}$ & $\begin{array}{l}505 \\
6.46 \%\end{array}$ & $\begin{array}{c}366 \\
6.44 \% \\
\end{array}$ & $\begin{array}{c}3,885 \\
15.42 \% \\
\end{array}$ & $\begin{array}{r}12,150 \\
12.98 \% \\
\end{array}$ & $\begin{array}{l}1,215 \\
1.39 \%\end{array}$ \\
\hline Minería ........................... & & & & & $\begin{array}{c}3 \\
.05 \% \\
\end{array}$ & $\begin{array}{l}59 \\
.23 \% \\
\end{array}$ & $\begin{array}{c}42 \\
.04 \% \\
\end{array}$ & $\begin{array}{c}13 \\
.01 \%\end{array}$ \\
\hline Petróleo y gas .............. & & & & & $\begin{array}{c}2 \\
.03 \%\end{array}$ & $\begin{array}{c}9 \\
.03 \%\end{array}$ & $\begin{array}{c}12 \\
.01 \%\end{array}$ & $\begin{array}{l}27 \\
.03 \%\end{array}$ \\
\hline Manufactura ... & $\begin{array}{c}7,221 \\
62.01 \%\end{array}$ & $\begin{array}{c}3,868 \\
45.32 \%\end{array}$ & $\begin{array}{l}10,626 \\
50.62 \%\end{array}$ & $\begin{array}{c}2,301 \\
29.43 \%\end{array}$ & $\begin{array}{c}1,075 \\
18.92 \%\end{array}$ & $\begin{array}{c}4,348 \\
17.26 \%\end{array}$ & $\begin{array}{l}9,124 \\
9.75 \%\end{array}$ & $\begin{array}{l}14,434 \\
16.62 \%\end{array}$ \\
\hline 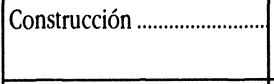 & & & & & $\begin{array}{c}11 \\
.11 \% \\
\end{array}$ & $\begin{array}{l}195 \\
.77 \% \\
\end{array}$ & $\begin{array}{l}2,412 \\
2.57 \%\end{array}$ & $\begin{array}{l}719 \\
.82 \%\end{array}$ \\
\hline Electricidad & & & & & $\begin{array}{c}1 \\
.01 \% \\
\end{array}$ & $\begin{array}{c}60 \\
.23 \% \\
\end{array}$ & $\begin{array}{l}132 \\
.14 \% \\
\end{array}$ & $\begin{array}{l}436 \\
.50 \%\end{array}$ \\
\hline 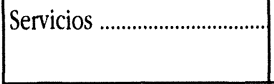 & $\begin{array}{c}3,456 \\
29.68 \% \\
\end{array}$ & $\begin{array}{c}4,323 \\
50.65 \% \\
\end{array}$ & $\begin{array}{r}9,890 \\
47.11 \% \\
\end{array}$ & $\begin{array}{c}2,936 \\
37.55 \% \\
\end{array}$ & $\begin{array}{c}3,236 \\
56.96 \%\end{array}$ & $\begin{array}{l}10,450 \\
41.49 \%\end{array}$ & $\begin{array}{l}31,911 \\
34.01 \%\end{array}$ & $\begin{array}{l}47,515 \\
54.72 \%\end{array}$ \\
\hline Transporte y Comunicación & & $\begin{array}{c}1 \\
.01 \% \\
\end{array}$ & $\begin{array}{c}4 \\
.01 \% \\
\end{array}$ & $\begin{array}{c}3 \\
.03 \% \\
\end{array}$ & $\begin{array}{l}36 \\
.63 \% \\
\end{array}$ & $\begin{array}{l}281 \\
.11 \% \\
\end{array}$ & $\begin{array}{l}1,439 \\
1.53 \% \\
\end{array}$ & $\begin{array}{l}1,349 \\
1.55 \% \\
\end{array}$ \\
\hline 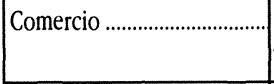 & $\begin{array}{c}355 \\
3.04 \% \\
\end{array}$ & $\begin{array}{c}287 \\
3.36 \% \\
\end{array}$ & $\begin{array}{c}307 \\
1.46 \% \\
\end{array}$ & $\begin{array}{l}345 \\
4.41 \%\end{array}$ & $\begin{array}{c}770 \\
13.55 \% \\
\end{array}$ & $\begin{array}{c}2,811 \\
11.12 \% \\
\end{array}$ & $\begin{array}{l}8,025 \\
8.57 \%\end{array}$ & $\begin{array}{l}17,735 \\
20.42 \%\end{array}$ \\
\hline $\begin{array}{l}\text { Insuficientemente } \\
\text { especificado .............. }\end{array}$ & $\begin{array}{c}612 \\
5.25 \% \\
\end{array}$ & $\begin{array}{l}39 \\
.45 \%\end{array}$ & $\begin{array}{c}18 \\
.08 \%\end{array}$ & $\begin{array}{c}1,727 \\
22.09 \%\end{array}$ & $\begin{array}{c}181 \\
3,18 \%\end{array}$ & $\begin{array}{c}3,095 \\
12.29 \%\end{array}$ & $\begin{array}{l}27,838 \\
29.75 \%\end{array}$ & $\begin{array}{l}3,377 \\
3.88 \%\end{array}$ \\
\hline $\begin{array}{l}\text { Desocupados que no } \\
\text { han trabajado }\end{array}$ & & & & & & & $\begin{array}{l}470 \\
.5 \%\end{array}$ & \\
\hline
\end{tabular}

Actualización a 1990 de Torres (1987). 
Según el último Censo de Población y Vivienda del Estado (1990), la presencia femenina en la actividad económica se ubica mayoritariamente en los servicios y en el comercio. Su participación en la manufactura ocupa el tercer lugar en cuanto a concentración de empleo femenino, con un $16.62 \%$, aunque hay claras evidencias de que este comportamiento sectorial se está modificando como consecuencia de la presencia del capital extranjero, a través de las plantas maquiladoras de exportación, las cuales desde su llegada han demandado, en esencia, fuerza de trabajo femenina, tal como se observa en la gráfica siguiente:

COMPOSICIÓN DEL EMPLEO DEL SECTOR MAQUILADOR POR SEXOS

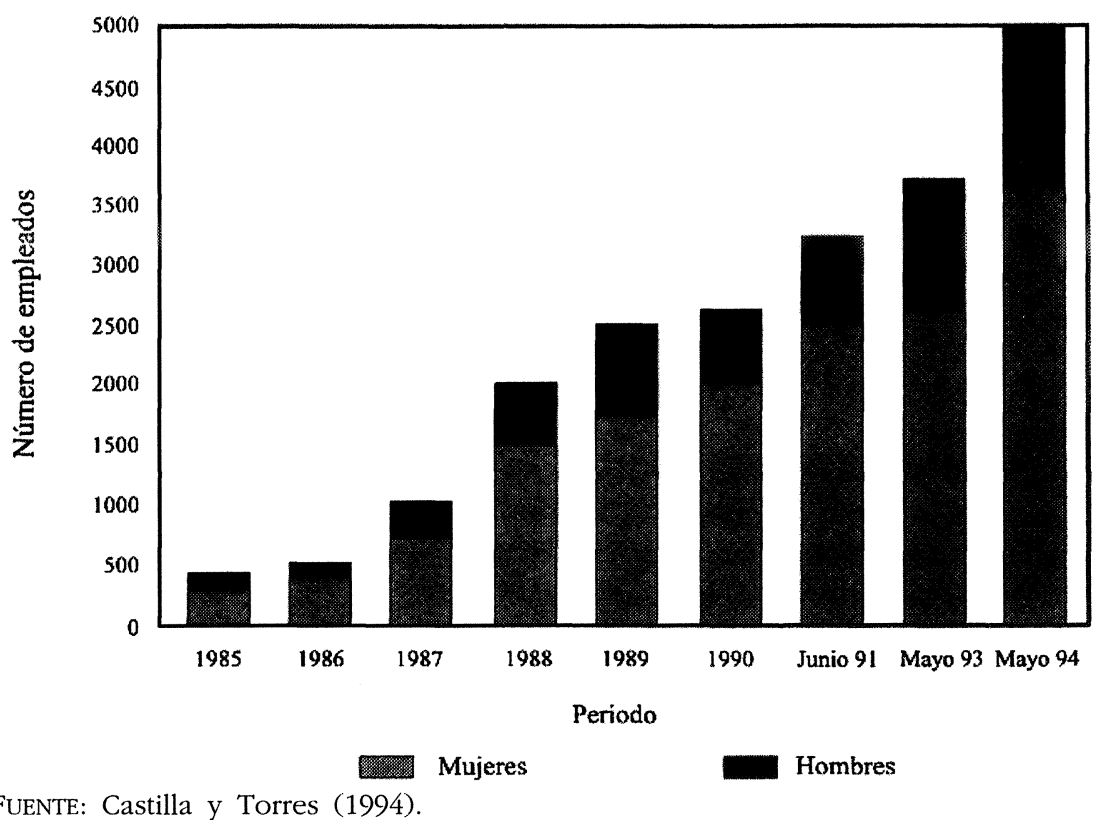

Un hecho interesante resulta la observación reciente de la masculinización de la fuerza de trabajo en estas fábricas, ubicadas sobre todo en las áreas rurales (confección, lavandería), por obvias razones de escasez de otras alternativas de empleo. Si bien los varones se encuentran más en las fases de corte o como supervisores, salta a la vista la presencia de costureros.

En este sentido, a la mujer yucateca ha correspondido el papel protagonista más importante en la gestación de este nuevo modelo de desarrollo. Este hecho no es fortuito, cuando menos, por dos cuestiones: en primer lugar, tradicionalmente dichas plantas han preferido ocupar mujeres por la naturaleza del proceso productivo de las tareas que allí se realizan. 
Durante varias décadas se trató de procesos exclusivamente de ensamble, intensivos en mano de obra, y de procesos de trabajo asociados a destrezas consideradas femeninas; minuciosas, detalladas, repetitivas. Actualmente, la modernización de dichos procesos — con la incorporación de tecnologías más sofisticadas, la transformación de algunas plantas en empresas manufactureras - ha modificado algunos aspectos del proceso de trabajo, propiciando la paulatina incursión de los varones a estas factorías; tal como se refleja en las últimas cifras del personal total recogidas en febrero de 1999 por el Instituto Nacional de Geografía Estadística (INEGI): $57.27 \%$ de la ocupación femenina en las maquiladoras de exportación extranjera contra un $85 \%$ registrado en los inicios del proyecto maquilador.

Sin embargo, cabe señalar que la actual participación femenina que ofrece el $57.27 \%$ en las plantas maquiladoras, aumenta a un $60.07 \%$ al considerarse únicamente el empleo a nivel obrero.

En segundo lugar, la herencia histórica artesanal de las mujeres mayas es ampliamente reconocida en el desarrollo de habilidades que se relacionan muy bien con las labores llevadas a cabo en las maquiladoras. Durante mucho tiempo, antes de la Colonia Española, las mujeres mayas yucatecas tejieron y bordaron mantas de algodón y por siglos se han abocado al arte del bordado de sus hermosos huipiles. Brevemente recordemos que también durante la colonia fueron ellas las que producían mantas de algodón para el extranjero. En aquel entonces, esas mantas constituían el equivalente de valor y la fuente principal de divisas para la región (García y Castilla 1982). Posteriormente, durante el esplendor henequenero, las mujeres trabajaron en las casas grandes de las haciendas. Sobre ellas recaían todas las tareas domésticas necesarias para su funcionamiento y mantenimiento, y ahí eran secuestradas para la confección de mantas de algodón.

Con el transcurrir de los años, las primeras noticias que existen sobre las mujeres yucatecas en trabajo fabril datan de 1836, año en que se instala la primera fábrica en Yucatán, "La Constancia", dedicada a la producción de textiles de algodón, y que dio empleo a numerosas mujeres y niñas, aunque, según García Quintanilla (1982), “el trabajo en las fábricas era visto de segunda clase, propio para presidiarios o mujeres". A partir de este hecho, aparecieron mujeres en industrias de cigarros y textiles, así como molenderas, tortilleras, costureras y en actividades relacionadas con la industria henequenera, como son las costaleras y corchadoras (de sogas de henequén). También se las encontró como domésticas, lavanderas, parteras, cocineras y profesoras. Como podrá observarse, salvo pequeñas variaciones, las mujeres se encuentran en ocupaciones consideradas propias de ellas, generalmente relacionadas con el trabajo doméstico, 
constituyendo muchas veces su salida de ese ámbito a la esfera pública: su carácter de doméstico o productivo.

Así, desde las primeras décadas de 1900 hasta finales de los años sesenta, la presencia de la mujer yucateca en la estructura económica fluctúo entre estas actividades y ocupaciones que por períodos aparecen y desaparecen, según las etapas de auge o depresión por las que atraviesa. Sin embargo, ya en los años setenta las cosas cambian; se observa un claro predominio del sector servicios sobre la manufactura: dominan las maestras, enfermeras, secretarias, recepcionistas, servicio doméstico, trabajadoras de limpieza y aseo, etc. Además ya no existen vacíos en ninguno de los rubros de la actividad económica y la mujer aparece en ocupaciones que tradicionalmente habían sido campo exclusivo de los varones. Estos cambios son consecuencia, por una parte, del creciente desarrollo capitalista que paulatinamente va absorbiendo actividades realizadas antes en el hogar, así como también por la modernización de los sectores económicos que vuelve indispensable el trabajo administrativo, ámbito considerado casi de exclusividad femenina. Por otra parte, el proceso de urbanización que tiene lugar en los años sesenta exige el desarrollo del comercio y los servicios, entre los que destacan los sociales de salud y educación, cuyas necesidades en cuanto al tipo de mano de obra coinciden con las características de la fuerza de trabajo femenina. En el sector manufacturero, la única rama en la que la presencia de mujeres es significativa es la del vestido, enfocada en su mayoría a la fabricación de ropa típica (guayaberas, bordado de huipiles). Se trata de una industria basada, de manera importante, en el trabajo domiciliario y en pequeños talleres de costura.

En los años ochenta y noventa la tendencia de concentración femenina en el comercio y servicios continúa, aunque la instalación de plantas maquiladoras repuntó la participación de la mujer yucateca en la manufactura, para posteriormente descender ${ }^{8}$ en relación a los hombres ocupados en estas plantas. Sin embargo, todavía, aparecen cotidianamente las mujeres yucatecas como las principales protagonistas de este tipo de plantas que, a partir de mediados de la década pasada, se fueron diseminando por todo el interior del Estado, impactando en las áreas rurales, donde la incorporación de la mujer al mercado de trabajo había revestido otras características, como la migración intermitente campo-ciudad, para trabajar como domésticas, y/o la integración en programas productivos gubernamentales como socias o sujetos de crédito.

En este sentido, la mujer rural también está siendo incorporada, de manera masiva, al trabajo fabril, a través de las maquiladoras. Según in-

8 No en términos absolutos, sino porcentuales como efecto de la incursión de los hombres en esta actividad 
formación proveniente de una encuesta realizada en la antigua zona henequenera de Yucatán por Albornoz (2000) se constata la presencia mayoritaria de la mujer como obrera de estas plantas en un $70 \%$. Cabe señalar que el $64 \%$ de los establecimientos corresponden al ramo textil (Ibid.), campo de actividades tradicionalmente femenino.

\section{LAS MAQUILADORAS EXTRANJERAS: VECTORES DE INNOVACIÓN PRODUCTIVA}

En trabajos anteriores ${ }^{9}$ hemos señalado que, en respuesta a los requerimientos internacionales, la presencia de la industria maquiladora en Yucatán ha venido aparejada a una distinta filosofía de trabajo que impulsa el nacimiento de un nuevo quehacer productivo, cuyos valores, actitudes y métodos se orientan hacia la eficiencia y el control de calidad. Esta nueva estrategia empresarial, que ha sido resumida por algunos investigadores en la fórmula Calidad Total-Justo a Tiempo, traslada el foco del análisis desde los costes hacia la participación e identificación del trabajador con la empresa, el trabajo en equipo, la filosofía cliente-proveedor, la mejora continua, círculos de calidad, la polivalencia, etc. (De la Garza et al. 1998). De tal suerte que los actores involucrados en la construcción de la nueva cultura de trabajo -empresarios, trabajadores y Estado- están creando como consecuencia nuevos marcos de relaciones sociales. En el ámbito de la fábrica destacan entre éstos, el sistema de relaciones industriales que acentúa una nueva gestión empresarial sustentada en la involucración de la mano de obra con la empresa, la flexibilidad en el uso de la fuerza de trabajo y la definición de los contenidos del trabajo. Dicho contenido descansa en la racionalidad del trabajo vivo, la incorporación reciente de nuevas tecnologías desconocidas para el medio -sobre todo en el ámbito organizativo e innovadoras formas de gestión de la mano de obra-. Un elemento central es que, en el ámbito de las relaciones laborales, aparecen nuevas formas de negociación directa entre los operarios y la empresa, ya que solo una de las plantas está sindicada.

Según se ha podido constatar en las distintas visitas a las fábricas que hemos realizado a lo largo del tiempo, el camino para los empresarios maquiladores, con respecto al tratamiento de la mano de obra, no ha sido fácil. El advenimiento del taylorismo en las plantas maquiladoras provocó

9 Desde 1985 hemos realizado distintos acercamientos a la industria maquiladora cuyos resultados han sido publicados en varias revistas locales y nacionales, e internacionales. 
de inmediato síntomas de rechazo, al contraponerse la racionalidad comandada por la disciplina productiva a una incipiente cultura laboral de fábrica, acostumbrada al trabajo a destajo y por ende a la regulación de sus tiempos. En cambio, los sistemas de trabajo en las plantas maquiladoras, importados desde sus países de origen, descansan en un riguroso control de los tiempos y movimientos del trabajo vivo. Situación que hoy día se ha estado modificando ante la continua resistencia obrera, expresada en una alta rotación de personal.

Es así como se originó la configuración y adaptación de la fuerza de trabajo de la mujer yucateca a los requerimientos de productividad en cantidad y calidad del capital extranjero. Al comienzo de operación de estas factorías, este proceso, que se acompañó de sistemas coercitivos para controlar el tiempo y los movimientos del trabajo en base al cronómetro, encontró una fuerte oposición por parte de las primeras obreras yucatecas, que tuvo como consecuencia inmediata, en una de las empresas de confección, una huelga general, presidida por un paro laboral y la manifestación pública de los hechos (Castilla et al. 1989: 102). La resistencia de las obreras yucatecas a esas exigencias productivas se expresó en la generalidad de las factorías en una rotación de personal, absentismo y abandono del trabajo. Hechos todos ellos que tuvieron, para los empresarios extranjeros, un significado de gran trascendencia, en términos de obligarlos a repensar la gestión de la fuerza de trabajo, desde una condición más humana.

Yucatán no es ajeno a los procesos reestructuradores que avanzan a nivel mundial, por ello actualmente el sector maquilador exportador está impactando los espacios fabriles locales con la introducción de nuevas tecnologías duras -en estricto sentido- o las denominadas blandas (tecnología organizacional), que inciden a su vez en la reorganización del trabajo, en la definición de sus contenidos y en la demanda de perfiles ocupacionales específicos para su desempeño. Dichos procesos conducen a la construcción de una cultura de trabajo gestada en una compleja interacción cotidiana entre los distintos actores involucrados en el quehacer productivo, mediante relaciones de cooperación, de negociación, así como de resistencia, en donde están presentes normas y valores culturales en el marco de nuevas relaciones contractuales vertebradas por la flexibilidad del trabajo. Al respecto hay que poner el acento en la heterogeneidad organizacional, tecnológica y laboral de las plantas maquiladoras que operan en el Estado bajo este régimen. De ahí que, como señalan Carrillo y Hualde, la industria maquiladora no corresponda de ninguna manera a un modelo productivo, tecnológico y laboral ${ }^{10}$.

${ }^{10}$ Investigadores del Colegio de la Frontera Norte, ubicado en Tijuana, México. 


\section{EL CONSENSO COMO TAREA PRINCIPAL DE LAS GESTIONES MODERNAS ${ }^{11}$}

Las empresas de hoy se han dado a la tarea de conocer, ensayar, adoptar y adaptar principios de novedosos sistemas productivos y en casos extremos intentar transferirlos en su totalidad. La intención es responder de manera positiva al proceso globalizador y a la creciente competitividad de los mercados. Sin embargo, en muchas ocasiones, las bondades de dichos sistemas productivos emergentes, ya probados en otras realidades, encuentran sus límites en su puesta en marcha con actores laborales de carne y hueso, constituidos de manera particular.

En este contexto, el ámbito de la gestión de los recursos humanos ha sido objeto de renovada atención por parte de las gerencias, como parte medular del tránsito a un nuevo paradigma productivo. Las prácticas con círculos de calidad, equipos de trabajo, tareas realizadas a través de módulos de producción, son algunas de las formas que reviste esta intención en el ámbito de la organización del trabajo. Por su parte, la búsqueda de reemplazo del conflicto por la negociación, la eliminación de los supervisores, las políticas de personal de puertas abiertas, la procuración de mayor convivencia entre trabajadores y directivos, la supresión de diferencias entre ellos (comedores y áreas de estacionamiento comunes), etc. son algunas de las novedosas formas correspondientes al espacio de las relaciones laborales puestas en marcha con el mismo objetivo.

Detrás de todo esto se encuentra una forma distinta de conceptualizar el trabajo humano en la producción, distanciada del taylorismo-fordismo que busca arrancar la máxima productividad posible de los hombres y las máquinas de las empresas, cerrándoles a aquéllos, cada vez más, los tiempos muertos del proceso productivo,a través de imponer ritmos y movimientos del trabajo. En contraposición, los modelos emergentes reconocen cada vez más la necesidad de la implicación de los trabajadores, del sentido de la iniciativa y de la movilización subjetiva de esos hombres y mujeres en los campos concernientes a la producción.

Así, de ser considerados éstos arena de enfrentamiento entre patrones y asalariados por la negociación del esfuerzo y el control -en sus diversas modalidades - como forma de disciplinamiento de los cuerpos, tendiente a la descalificación del trabajo, la discusión contemporánea apunta al reto que hoy enfrentan los empresarios en su búsqueda incesante de

1 Este apartado forma parte de la tesis doctoral en proceso de Beatriz Torres Góngora, Modernización productiva, reorganización de la producción y relaciones de trabajo en la industria de Alimentos y Bebidas de Yucatán. UAM-Iztapalapa, México, D.F. 
nuevas formas de disciplinamiento: la refuncionalización de la cultura a través de la adecuación de los valores y la apropiación de la subjetividad obrera, a fin de hacerla coincidir con los requerimientos empresariales encaminados a la eficiencia y a la calidad.

La imprevisibilidad del comportamiento laboral dentro del proceso de trabajo sigue siendo uno de los problemas centrales de la gestión, por su incidencia en la producción (Bilbao 1999).Los estudiosos de la red GERPISA ${ }^{12}$ (1996) se refieren a ella como la incertidumbre del trabajo y la consideran como una de las dos preocupaciones - la otra es la incertidumbre del mercado- que orientan la búsqueda de modelos productivos alternativos al taylorismo-fordismo, que, a juicio de esos expertos, ya no es funcional en las nuevas condiciones de la diversificación de la demanda y del mercado competitivo.

Se abre así, según Bilbao, una tendencia creciente hacia el consenso en la producción, que no existía en el período anterior. "En esta nueva situación del consenso, la dirección recupera su autonomía. Las adaptaciones a las condiciones cambiantes del mercado, requieren una rápida respuesta, incompatible con los avatares de la producción. De tal suerte que las nuevas formas de organizar el trabajo se vinculen a la flexibilidad en sus distintas facetas" (1999: 163). Teóricamente, hoy la vuelta de atención a los recursos humanos presenta dos direcciones: la llamada forma neoclásica que ve al trabajo como un coste susceptible de reducción - al igual que los otros factores productivos- a partir de un uso más eficiente de la fuerza de trabajo, lo que generalmente desencadena consecuencias precarizadoras para la mano de obra, y la Toyotista, asociada a la búsqueda de una nueva cultura de trabajo que tienda a conseguir el involucramiento de la mano de obra (De la Garza y Campillo 1998). Esto es, la adopción de modalidades de gestión fundamentadas en el reconocimiento y participación activa de los y las trabajadoras en la producción.

En esta misma dirección, la discusión contemporánea apunta el reto que hoy enfrentan los empresarios en su orientación hacia las nuevas formas de participación de la mano de obra en las empresas, y es cuando aparece en el escenario laboral la cultura, con cuyo manejo se pretende adecuar los valores y la subjetividad obrera con el propósito de hacerlos coincidir con los requerimienios empresariales encaminados a la eficiencia y a la calidad. Por ello, las gestiones modernas se han lanzado a lo que Linhart (1997) ha denominado la batalla de la identidad, consistente

12 Groupe des Etudes et de Recherches Permanent sur L'Industrie et les Salariés de L'Automovile. 
en "modernizar la mente de los asalariados, es decir, en conseguir que éstos interioricen los valores y la cultura de la empresa, adopten sistemáticamente métodos estándar de razonamiento, en 'formatearles' una mente gestionaria y empresarial. Eso sí, partiendo de la racionalidad dominante de la empresa... se trata de obligarles a renunciar a la solidaridad de la profesión, de la clase para adoptar únicamente los valores de la empresan.

En este sentido, en el mundo laboral de hoy se habla del buen y mal camino del trabajo (Milkman 1997), en virtud de que al parecer las transformaciones, en la generalidad de los centros laborales, se mantienen a nivel del discurso, sobre todo en países no hegemónicos. La experiencia empírica registra que un gran número de empresas continúan trabajando con formas de gestión caracterizadas por supervisiones autoritarias de arriba abajo, y los cambios introducidos en la fábrica se refieren más que nada a mecanismos empresariales para trasladar las funciones de control hacia los mismos trabajadores, a través de la interpelación de su subjetividad y a la vigilancia mutua a raíz de los grupos de trabajo ${ }^{13}$.

Yoshihara (1989) señala que, desde la segunda mitad de la década del setenta, se ha incrementado la presencia de corporaciones japonesas en países desarrollados, especialmente en los EE UU y, en consecuencia, la norma ha sido introducir el estilo japonés de producción, integrado en esencia por tres componentes: equipamiento tecnológico, tecnología de producción y clima organizacional en la empresa. A través de este modelo se han transferido el know bow para el control de calidad y los sistemas de entrega programada, así como los círculos de calidad ampliamente difundidos. Asimismo, como condición sine qua non para la producción de artículos de alta calidad y productividad, este modelo pone énfasis en la equidad, la atención al detalle, los grupos de trabajo, y las llamadas cinco S, orientadas al aspecto organizacional, que subrayan el orden, la disciplina y la limpieza.

Estas consideraciones introducen el estudio de caso que a continuación presentaremos, en virtud de que esta empresa en estudio sustenta su filosofía, su organización de la producción y sus relaciones laborales en componentes del management japonés trasladados a Yucatán desde su matriz, ubicada en los Estados Unidos de Norteamérica.

13 Para el caso de Yucatán, esto se ha constatado a través de una encuesta en 50 establecimientos manufactureros. Se encontraron signos de precariedad tanto en los niveles tecnológicos como en la organización del trabajo y las relaciones laborales, registrándose, en ese entonces, pocas empresas que hubieran iniciado procesos reestructuradores (Castilla y Torres 1997). 


\section{MOLDEANDO NUEVAS FIGURAS OBRERAS. El CASO DE UNA MAQUILADORA ESTADOUNIDENSE EN YUCATÁN ${ }^{14}$}

ORMEX de México ${ }^{15}$ nace en el contexto del hermanamiento de ciudades emprendido entre Mérida y Glendora, antes del proyecto maquilador oficial puesto en marcha en 1985. Lo atractivo de esta empresa - perteneciente a un corporativo líder mundial en aparatos dentales- es que su expansión y crecimiento han sido acompañados de cambios sustanciales en sus trayectorias tecnológicas y en el crecimiento de su personal altamente capacitado; de ensambladora en sus inicios a manufactura con tecnología semiautomatizada, hoy día cuenta con procesos realizados con alta tecnología microelectrónica. Desde este punto de vista, siguiendo la clasificación de Jorge Carrillo y Alfredo Hualde ${ }^{16}$, es considerada una planta de segunda generación. Esta severación se ve confirmada al ser nombrada Planta Modelo por las revistas Mexican Investement Board y Twin plants, en sus ediciones de diciembre de 1999 y 1998, respectivamente. En una nota consignada recientemente en la prensa local ${ }^{17}$, el gerente de la empresa mencionó que la compra de la Cía. Analityc Endodontics, por el Corporativo Sybron Dental Specialys, al que pertenece Ormex, implicó una fuerte inversión de 120.000 dólares (por unidad), dedicada a los brazos robotizados, cuya función es dar los últimos toques a las limas de níquel y titanio, así como la compra de ocho modernas máquinas robóticas, con un precio cada una de 350.000 dólares, para la elaboración de limas con alta precisión.

En lo que respecta a la producción, el entrevistado señaló un incremento de 80.000 horas estándares de producción al mes, dato que implica un crecimiento de la productividad de ocho veces, ya que en 1984 la cifra registrada era de 10.000 horas. Por último el gerente anunció un crecimiento de la empresa a corto plazo con la generación de 600 empleos más.

14 Cabe señalar que esta fabrica no es representativa de las maquiladoras, tanto por su gestión, filosofía y la identidad de los trabajadores con la empresa, como por el proceso productivo que resulta muy diferente a la confección. Hecho este último que lo hace más atractivo e incluso seductor, como declararon algunas de las trabajadoras entrevistadas. Ello sustentado en el manejo de las máquinas.

15 Esta investigación forma parte de la tesis doctoral de B. Castilla Ramos, Nouvelles technologies et changements culturels chez les ouvrieres mayas travaillant dans une usine de montage americaine au Yucatán, Mexique. Universidad de Perpignan, Francia. En proceso.

16 Investigadores del Colegio de la Frontera Norte, Tijuana, México.

17 Diario de Yucatán, marzo del 2000 
El éxito de esta filial estadounidense, esencialmente femenina ${ }^{18}-$ situada en el Municipio de Umán, frente a una exhacienda henequera- se sintetiza en su salud laboral expresada en la alta calidad de sus productos, exportados a los cuatro continentes y certificados por la Unión Europea y otras organizaciones mundiales de calidad. En lo que respecta a sus trabajadores (as) resalta su baja rotación y absentismo, así como la identidad que tienen con la empresa, hechos que se expresan en la estabilidad en el empleo, así como en la antigüedad de la fábrica, que ha cumplido 19 años de operación en Yucatán.

Es difícil sospechar que en una zona deprimida del Estado, a escasa distancia de la exhacienda henequenera Itzincab, cuya casa de máquinas en ruinas se mantiene como un elocuente testimonio de la época dorada del llamado oro verde, se ubique - solamente separado por una carretera, y hoy unida por un puente- un mundo opuesto, encarnado en una empresa estadounidense representativa de la administración y producción japonesa en lejanos y ajenos espacios. El contraste entre estas dos realidades; la del espacio fabril, con sus innovadores sistemas de manaegment y de tecnologías sofisticadas - brazos electrónicos y máquinas de control numérico computarizado-, y la del tejido social en donde la fábrica se ha instalado, se presentan como laboratorios de inusitadas experiencias.

El encuentro de estos mundos tan distantes en el espacio fabril está dando como resultado la emergencia de figuras obreras con una nueva cultura de trabajo, que es orientada a través de programas de ingeniería cultural que pretenden adecuar los valores de los y las trabajadoras a las nuevas exigencias productivas.

Uno de los hallazgos más importantes de la investigación fue descubrir que las obreras de esta factoría extranjera, hijas o nietas de campesinos mayas, se convierten en una nueva figura para la entidad. Orgullosas de su empresa y de su trabajo, que se vende lejos, se entregan solícitas a un mismo equipo cuya meta final es producir con alta calidad y eficiencia. Los emotivos testimonios expresados por más de trescientas obreras, comienzan a dibujar posibles respuestas: el hambre, y la descalificación, el desempleo abierto y la precariedad de las ocupaciones de sus esposos y padres, y desde luego las escasas oportunidades que tienen ellas mismas de ser ocupadas en otros empleos que las dignifiquen, constituyen los escenarios en donde hay que situar la primera mirada. Cabe

18 Como dato interesante, tanto la gerente de Recursos Humanos, como varias de las Supervisoras (Ingenieras en Producción) son mujeres. De ahí que resulte sugerente considerar la gestión de la empresa concerniente a la mano de obra, atravesada por relaciones de género. 
destacar que muchas de ellas son el eje de sus hogares, en tanto que proveen la seguridad social, la estabilidad en el ingreso y otras prestaciones adquiridas a través de su empleo. Al respecto resulta interesante señalar que en el censo realizado en la fábrica solo un $13 \%$ declaró abiertamente ser la jefa de familia (madres solteras o hijas), ya que por razones culturales resultan ser los jefes de los grupos domésticos, los padres, las madres o los esposos, que son designados por ellas mismas como jefes. El análisis de la información con respecto a las ocupaciones de éstos últimos, a sus ingresos, sus ocupaciones informales y su inactividad ocupacional en el mercado de trabajo (madres de familia o jubilados), los convierten, sin duda, en jefes simbólicos.

Sorprende así mismo la lealtad expresada por las trabajadoras hacia la empresa. Lealtad que tiene que ser entendida desde su referente histórico y social, que implica formas de relación comunitarias y de solidaridad, que las nuevas obreras reproducen en la fábrica desde el momento en el que reclutan a sus compañeras de trabajo en el seno de sus familias y comunidades, así como en la contemporaneidad explicada en las escasas y precarias oportunidades de empleo que la economía local brinda a este sector de población femenina. En el aspecto de las trayectorias laborales, el censo mencionado reveló (Castilla et al 1997) que un $80 \%$ de la población entrevistada declaró haber trabajado anteriormente en empleos que se encontraban en una notoria desventaja con respecto a su empleo actual: altamente precarios, signados por la eventualidad, la carencia de prestaciones que marca la ley y con posibilidades nulas de crecimiento dentro de la empresa y, sobre todo, en lo que ellas denominaron el trato, refiriéndose en algunos casos al trato déspota recibido por sus patronos. Hechos todos ellos que confieren un significado diferente a su trabajo en la fábrica. Por eso, las obreras que ya han interiorizado la disciplina fabril, expresan su compromiso con la empresa en la actitud positiva hacia el trabajo y en la gratitud hacia ella, en una respuesta compensatoria al reconocimiento de su labor y a los incentivos otorgados por su eficiente desempeño.

Los dispositivos administrativos que sedimenta la construcción de la cultura de trabajo, se ubican en la gestión, definida por su gerente general como Liderazgo Participativo, que se apuntala en la teoría de las relaciones humanas y en componentes propios del denominado Management japonés; de ahí que la fábrica adquiera una nueva imagen en el contexto del panorama industrial de la entidad. La imagen de una autoridad empresarial que se preocupa por el factor humano y, en correspondencia, la mano de obra deviene orgullosa y delicada.

La búsqueda de la calidad total en la producción es procurada a partir de dispositivos administrativos que tienen como meta humanizar el tra- 
bajo y promover un trabajador participativo que se encuentra interpelado por un ambiente laboral que reclama nuevas actitudes y habilidades, de tal suerte que la integración entre operarios y empresa se realiza en el marco de relaciones cordiales, que se convierten en el eje de la nueva fábrica. El sistema de relaciones laborales que abarca todo lo que subyace a la cultura de la calidad se sustenta en lo que en el lenguaje empresarial ha sido denominado el nivel de confianza: "Nuestro deber es fortalecer el contacto y la comunicación con el personal, y apoyarlas tanto en el trabajo como en su aspecto personal. Somos conscientes de que la gente trabaja muy duro, rinde mucho" (Gerenta de Recursos Humanos, 12 años de antigüedad).

Es así como la democracia en la fábrica se convierte en el lema de la vida cotidiana de la empresa y ésta se observa en las puertas abiertas de los distintos gerentes a quienes las obreras tendrán acceso si así lo desean. En congruencia con la política de apertura y de convivencia entre empresarios y trabajadores, desaparece del escenario fabril el protocolo y se fomenta la equidad. Para sorpresa de las trabajadoras, los jefes son simplemente tuteados y llamados por su nombre, con ellos comparten el mismo comedor, donde todo el personal —sin distinción alguna- adquiere gratuitamente los mismos alimentos.

En el ámbito de la producción, el reconocimiento y desarrollo de las trabajadoras por la gerencia se expresa en el sistema de las Competencias Laborales, implementado por el llamado Programa de Niveles, definido como un procedimiento para motivar al personal para que pueda ser ascendido de acuerdo con sus capacidades, reconocer su esfuerzo y desarrollar sus habilidades en la elaboración de varios productos "de tal forma que gane más quién más operaciones domine y además demuestre otras características personales como son cooperación, buena conducta, etc. Para que un trabajador pueda ascender tiene que probar destre$\mathrm{za}$ en las operaciones requeridas cumpliendo o sobrepasando los estándares en la cantidad y calidad del trabajo, cooperación, disciplina, seguridad y orden".

El mercado interno de trabajo que funciona como un incentivo al crecimiento del personal en el seno de la empresa, plasmado en el mencionado Programa de Niveles, se traduce en imágenes guias para las obreras que anhelan convertirse algún día en inspectoras de control de calidad, asistentes o auditoras de producción, o llegar a las oficinas como auxiliares de administración. La presencia en la robótica de trabajadoras expertas, sin estudios formales, atestigua la política decidida de la empresa de promover a su personal, en virtud de que éstas áreas exigen nuevas figuras obreras con cualificaciones de tipo técnico, de preferencia masculina. 
Esto último pensado en las exigencias productivas que requieren horarios escalonados ${ }^{19}$.

Otro aspecto interesante lo constituye la creatividad de las trabajadoras, impulsada por la fábrica en los espacios de intervención obrera en el proceso de trabajo. Lo anterior se sostiene según los directivos de la planta, en la destreza que las trabajadoras han adquirido en el proceso productivo. Según las declaraciones de una de las supervisoras de producción entrevistadas: ‘[...] la práctica anterior da muy buenos resultados porque ellas plantean las sugerencias, mismas que resultan esenciales para el quehacer productivo, en virtud de que son ellas las que realizan el trabajo [...].

En lo que concierne a las relaciones laborales, uno de los hallazgos más interesantes constituyó la representatividad que tienen los trabajadores, a partir de dos instancias jurídicas: Las juntas semanales de trabajadora con los supervisores (as) de área y la Junta de Representación de trabajadoras. En ambos organismos participan obreros (as), dirigentes, en la toma de decisiones que competen a la producción: turnos, horas extras, organización del trabajo, así como asuntos periféricos a estos, concluyendo los acuerdos de las seciones en una minuta que es presentada a todo el personal de la fábrica, con la intención de recoger sus sugerencias. Cabe señalar que los (las) representantes de trabajadores (as) por cada área se rotan cada seis meses y las juntas se llevan a cabo mensualmente con la gerencias (de recursos humanos o con el gerente general). Dicha práctica proviene de la casa matriz y funciona en la planta desde su creación en 1982.

Pero la efectividad de este nuevo esquema de gestión empresarial no puede comprenderse si no ponemos un pie en la historia: en el entramado social yucateco, conformado por relaciones de dependencia personal e impregnado de una fuerte tradición mesoamericana que nos pone frente a un padre responsable ${ }^{20}$, así como un régimen de trabajo que si bien ha sido de sojuzgamiento, ha otorgado cierta tutela a los trabajadores.

Desde nuestra óptica, los largos siglos de explotación que padeció el maya yucateco a partir de los sistemas de trabajo y organizaciones introducidas por la sociedad colonial no fueron liberados por la Independencia de México, ya que su condición de subordinados prevaleció, al aparecer nuevos patrones en escena cuya posición de propietarios de las haciendas henequeneras los transformaría en sirvientes acasillados $\mathrm{o}$, para algunos autores, en esclavos. En este sentido, el modelo maquilador de exportación viene a ocupar el lugar cedido por las plantaciones heneque-

19 Todo ello apuntalado en un paquete de prestaciones que para las trabajadoras es interpretado como la maquiladora numero uno en el Estado.

20 García Quintanilla, comunicación personal. 
neras y en consecuencia surgen nuevos capitales de empresas, ahora con registros internacionales.

\section{EMERGENCIA DE NUEVAS FIGURAS OBRERAS ${ }^{21}$}

Recientemente se registra la presencia de la robótica en la fábrica, al mismo tiempo que se celebran las fiestas de la comunidad de Itzincab, de profundas raíces históricas, y es cuando se analiza este aspecto en los dos mundos: la empresa y la comunidad. La propuesta metodológica para el análisis se teje en torno al llamado enfoque de la llamada "Sociología de la emergencia" y de "la Dinámica Cultural", corriente que subraya el análisis de la identidad en construcción de sujetos actores, constructores del cambio cultural y de la vida social, a partir de la instauración de nuevos procesos económicos y sociales (Pavageau 1994). En el caso que nos ocupa, la empresa resulta el agente de cambio más importante. En este punto resultaron de gran relevancia y fuente de inspiración los estudios de Jean Pavageau y Philippe Schaffhauser (1995) acerca de los migrantes de Tarecuato - pequeña comunidad del centro de México- a los EE UU, donde la movilidad de los hombres es acompañada de la movilidad de modelos. Es decir, si bien la emigración se sustenta en necesidades económicas, los autores ponen en realce la existencia de otros factores más sutiles, como son: sus sueños, sus aspiraciones y sus deseos de ampliar horizontes, que los conducen a emprender la aventura de cruzar la frontera para establecerse en California. De ahí que se proponga una sugerente analogía entre los migrantes Purépechas que cruzan la frontera, y las hijas o nietas de campesinos mayas que cruzan el puente que atraviesa la carretera para incorporarse al trabajo fabril en búsqueda de nuevas expectativas. Desde esta perspectiva de análisis, el acercamiento a las trabajadoras, protagonistas de esta investigación, resulta más humano. Así, sin soslayar el aspecto económico, escuchamos en silencio sus deseos, sus sueños, sus aspiraciones, sus representaciones simbólicas, sus sorprendentes discursos, al mismo tiempo que prestamos atención a sus prácticas sociales, derivadas de sus experiencias en la empresa, a partir de la introduc-

${ }^{21}$ Sobre este tema se filmó el documental que lleva como título: "Las que cruzaron el puente: trabajo fabril y comunidad" por B. Castilla (investigadora y productora), R. Domínguez (realizadora), Tony (cámara) y M. Salazar (editor). El trabajo fue financiado por el programa SUPERA, ANNUIES, Mérida Yucatán, 1997 y fue presentado en su versión francesa: "Celles qui ont passé le pont: travail en usine et communaute" en la Universidad de Perpignan, en el coloquio Les formmes de reconnaisance de l'autre en question, mayo, 2000. 
ción de los cambios en la organización del trabajo que demandan una mayor flexibilidad de la mano de obra ${ }^{22}$. Todos estos aspectos favorecen, sin duda, en las trabajadoras, la toma de conciencia, la emergencia de nuevos discursos, de energías creadoras y prácticas diferentes, sin romper por ello con su vida comunitaria ${ }^{23}$.

La hipótesis que posibilita la interpretación de los discursos de las obreras la aporta Reygadas (1998) al señalar que, al producir significados en torno a su actividad fabril, las trabajadoras están haciendo uso de un capital simbólico más amplio que se ha venido construyendo en diferentes momentos de sus trayectorias laborales, en sus comunidades, en sus grupos domésticos y en el seno de su cultura, y desde la profundidad de su historia. Los testimonios de las informantes, presentados a manera de relatos de vida de cuatro trabajadoras de la empresa, nos detallan su percepción y relación a partir de la convivencia con las nuevas tecnologías, la manera en la que elaboran sus experiencias, el cambio en las relaciones de poder - dentro de la fábrica y en sus vidas personales-, el grado de control sobre su actividad productiva, los espacios de autonomía y libertad frente al puesto de trabajo, así como el impacto de este nuevo quehacer productivo en la cotidianidad de sus vidas. Queda así mismo de manifiesto que desde la óptica de la fábrica, la concepción acerca de la tecnología rebasa el concepto reduccionista que se circunscribe al de las máquinas, al concebir la interrelación de éstas con los hombres. En palabras de Arnulfo Arteaga (2000) «[...] la calificación, la adaptabilidad, y la motivación del componente humano, permiten delegar un conjunto de funciones vitales y asegurar el control humano de la organización de la producción". Solo en este sentido, el concepto de tecnología adquiere su significado auténtico.

Los relatos de vida reflejan, asimismo, la interiorización de un conjunto de valores y la visión del mundo que corresponden al discurso planteado por la empresa en la instauración y reforzamiento del modelo de producción, que promueve la calidad total, el espíritu de equipo, la participación y la expresión de sus puntos de vista. En este último punto, Palenzuela (1995) precisa que la ideología sobre el trabajo se traduce en

${ }^{22}$ En virtud de la exigencia de la sincronización perfecta entre la demanda internacional y la producción.

23 Cabe mencionar que una de las trabajadoras entusiastas denunció ante la prensa (Diario de Yucatán, 3 de noviembre de 1999, Mérida, Yucatán) a las autoridades, por el abandono en que estaba la hacienda Itzincab. Motivo por el cual fue afectada gravemente por las inundaciones recientes, con las consecuentes pérdidas materiales en los hogares de sus habitantes. 
un conjunto de valores, de representaciones y percepciones que las obreras interiorizan en su actividad laboral y que conllevan modificaciones substanciales en sus prácticas sociales, así como en la reconstitución de sus identidades (Commailles 1993).

\section{A MANERA DE COMENTARIO FINAL}

La aseveración de Miller y O'Leary (citada por Lahera 1998), de que los centros de trabajo resultan ser laboratorios culturales, resulta sugestiva en la comprensión de este ensayo, en tanto que dichos autores señalan que en las fábricas no sólo se producen bienes tangibles sino también nuevos tipos de trabajadores (flexibles, emprendedores). Para el caso que nos ocupa, la emergencia de una nueva figura obrera femenina orgullosa de su trabajo, se sustenta, como hemos visto a lo largo de la exposición, en la gestión empresarial que pone el acento en la revalorización del trabajo humano con miras a reforzar la autoestima de las trabajadoras, que se traduce en la mirada de los actores en el espacio de la fábrica. Este proceso lleva, asimismo, a la identidad de grupo ${ }^{24}$, pero también tiene que ver con la matriz sociocultural en la que se encuentra instalada esta empresa, en donde se interrelacionan una multiplicidad de factores culturales, históricos, sociales. Por tal motivo, apunta el citado autor "que las relaciones entre la fábrica y la comunidad solo pueden comprenderse a partir de estos dos planos, en virtud de que los trabajadores acceden a la fábrica con un equipamiento cultural y contextual con respecto al espacio temporal, y que desde esta óptica se posibilita la comprensión de las vivencias construídas al interior de los muros de la fábrica" (Lahera 1998). En el trabajo realizado en la comunidad, se constata la revalorización que ha adquirido la mujer en sus hogares, en el desempeño de sus roles tanto en su propia vida, como frente a sus familias. El investigador Jaques Commaille (1993), ha caracterizado este último punto como "Les regards des autres".

Como punto final, puede decirse que a la mujer yucateca le ha tocado el papel protagónico de iniciar un nuevo proceso de relaciones labo-

24 Esta aseveración se consignó tanto en las entrevistas realizadas con las trabajadoras, como en los grupos de discusión mantenidos en la fábrica con todo el personal, en torno al primer documental realizado como un sondeo exploratorio en sus hogares. Este lleva como título: "Dos Tiempos, dos mundos: El Santo Cristo del Amor». B. Castilla (investigadora y productora), R. Domínguez (realizadora), Francisco Fernández (q.p.d.) (Cámara) y M. Salazar (Editor). Con financiación del PROGRAMA SUPERA ANNUIES, Mérida, Yucatán 1997 
rales determinadas por el capital extranjero. A diferencia de las relaciones comenzadas en el siglo pasado con la gran explotación henequenera, ahora esta relación capital-trabajo se personaliza en el espacio fabril. A lo largo del tiempo, este proceso ha adquirido diferentes matices: resistencia pasiva, paros laborales y, actualmente, la presión para conseguir mejores condiciones de trabajo, como lo ejemplifica el estudio de caso presentado, que si bien resulta atípico, actualmente es contemplado por los maquiladores, extranjeros y locales, como un modelo que sugiere la reflexión.

\section{ANEXO I. ENTREVISTAS ${ }^{25}$}

Área endoautomatizado.

1. Verónica Botello. 8 años de antigüedad. Asistente de producción.

El área se llama endoautomizado, y soy asistente de producción: Llegué aqui porque la empresa me designó,. Estuve cuatro meses en capacitación aprendiendo el manejo de las máquinas ensambladoras y láser.

La diferencia que existe entre estas máquinas y las anteriores es que estas máquinas trabajan solas, y las anteriores no, uno las tenia que trabajar, por eso en éstas el trabajo es más fácil, porque uno solo calibra y cambia de material

Lo que bago abi es ayudar a las muchachas a reparar sus máquinas, a calibrar y la máquina trabaja sola, y cuando falta personal yo misma opero las máquinas.

- ¿Piensas que la trabajadora se siente más importante con este trabajo?

Considero que sí, porque se sienten más seguras de su trabajo. Tienen que estar vigilando el proceso, porque si se deja a la máquina trabajar sola, pueden salir mal las piezas, y de ser asi la operadora las detecta antes de que las ensamble el robot.

Me gusta mucho mi trabajo, quisiera aprender el trabajo de otras áreas.

2. Lucy Cano. 6 años de antigüedad. Operadora endoautomatizado.

En el momento que mi papá no me pudo seguir manteniendo, me vine a Mérida, más bien me rebelé. No querian que viniera, yo era muy noble, muy callada, era la única mujer en mi casa y todo era para los varones. El estudio para los varones, y las mujeres que se queden en su casa, porque se casan y el marido las mantiene, y por eso no pude seguir estudiando. Pero yo quería superarme, pero no sabía cómo, pero busqué la manera. Hace 15 años que dejé mi pueblo y vine a casa de una tía. Empecé a trabajar como dependiente de mostrador en una mercería, hasta que entré a la empresa. Abi estuve durante cinco años en el área de "mesh", hasta que me pasaron a endoautomatizado.

Extraño mi pueblo y al principio fue terrible, de hecho me costó mucho trabajo estar en Mérida, y extrañé todo lo que bay abi, creo que cuando tienes las cosas no las valoras en el momento, y cuando no las tienes dices que bonito era, pero tenía que superarme y esa era mi meta. Mi padre era campesino y trabajaba la tierra, y yo que-

25 Estos relatos son extractos de los discursos de las obreras, que aparecen en el documental antes citado (Castilla et al. 2000), que forma parte de la tesis doctoral en proceso de B. Castilla. 
ría saber, y como el no me pudo costear mis estudios. Yo sabia que sin estudios muchas veces no se puede, pero cuando uno quiere algo, sigues y sigues hasta donde puedas. Yo soy de esas personas que dice: hasta donde yo pueda.

- ¿Cómo te sientes en esta nueva área?

-Ocurre, que tienes miedo, pero tienes que aprender, tu te dices a ti misma, tienes que superarte, $y$ dices tengo que aprender, tengo que superarme, tengo que intentarlo, tengo que poder hasta donde yo pueda, hasta donde mi capacidad me de, hasta... no sé, hasta donde yo pueda llegar, yo creo que no hay límites. La empresa va creciendo, y espero que siga creciendo para ir aprendiendo más cosas, y mientras te den la oportunidad... Yo siento que doy todo de mi misma para aprender y trato de aprender porque me gusta superarme.

-Lucy, cuáles son tus aspiraciones?

- Como be dicho, soy una persona que me gusta superarme, abora estoy tramitando mi casa, por eso no me gustaría dejar la empresa, tengo mis metas, si en algún momento me dan mi casa pondré un negocio. Quiero ser mi propio patrón. No quiero tener patrón, quiero tener mis propias cosas.

Área de "Mesh"

3. Manuela Caamal. 12 años de antigüedad. Inspectora de Calidad.

¿Podrías decirnos qué cambios ha observado en las jóvenes de Itzincab, desde que trabajan en la empresa?

-Muchas cosas han cambiado, por ejemplo, las muchachas antes iban a trabajar en las casas a lavar a planchar a trapear, y a partir de que abrió la fábrica muchas han venido a trabajar aqui. Aunque no tienen los estudios "secundaria" "bachillerato", ORMEX, las ha aceptado, a veces incluso sin concluir la escuela Primaria. Y eso les ha ayudado mucho, y veo que también ellas están cambiando. Abora en la hacienda ya no ves a las muchachas de sirvientas, sino que buscan un trabajo en una empresa, y yo pienso que eso es importante, porque la mayoría de ellas sólo saben leer y escribir, y al trabajar en las fábricas les ayuda bastante. Ya no tienen la misma forma de pensar, ya no están encerradas en su casas, visten diferente. Ya se nota el cambio. Las muchachas visten moderno, se ocupan de reparar sus casas, nosotros éramos muy pobres, abora ya techamos nuestras casas. Mi casa era de lámina, entonces cuando yo venia a trabajar y llovia, mis compañeras me preguntan ¿por qué estas nerviosa? Y yo les decía: porque aborita está entrando agua a mi casa... Y eso be observado también en las muchachas que ayudan a sus papás a componer sus casas, y a mi me da mucho gusto que las muchachas se estén superando así.. Nosotros somos 10 bermanos, y yo le decía a mi mamá: "no me voy a casar pronto, te voy a componer tu casa", y eso fue lo primero que bice. Arreglé la casa grande (principal), y ahora está feliz mi madre y abi vivimos (en el mismo predio), más o menos contentos.

- ¿Y qué piensan los esposos con respecto al trabajo de sus mujeres?

- Yo escucho que muchos esposos les dicen a sus esposas que no trabajen porque ellos están trabajando. $Y$ esto es lo primero que friega a la mujer, porque al dejar de trabajar todo vuelve a cambiar. Empiezas por darte cuenta que te bacen falta muchas cosas, porque el hombre puede dar la comida, y para los niños, pero para ti no hay. Por eso al renunciar las señoras se dan cuenta de todo lo que les hace falta. Yo pienso que las parejas deben de ponerse de acuerdo para analizar esa situación. 
Cabe señalar que durante las inundaciones ocurridas en noviembre de 1999 en la bacienda de Itzincab esta trabajadora denunció ante la prensa la precariedad de los babitantes de las viviendas de la bacienda y sus calles no pavimentadas y desniveladas. Ella fue quien gestó la pavimentación de las calles de la comunidad.

Área de limas

Reyna Isabel Caamal. Asistente de Producción.

Ya creció bastante, ya avanzó bastante, bay mucha gente nueva y eso es bueno, a mi me gusta, me gusta que haya mucho trabajo en la fábrica. Hay mucho material y esto es bueno, porque es tanto el material que te dedicas más al material y eso es bueno también para acá (fábrica). Hay mucha gente que viene a buscar trabajo, y jporqué para ellos no? (varones). Pues si es un cambio total porque tratar con bombres no es igual que con las mujeres, no buscas cómo bablarles, cómo decirles, cómo explicarles. Hay algunos que si salen bastante abusados, porque le explicas una vez y lo que les explicas, si lo entienden. Hay otros que como en todo, les explicas y como que se va al aire, a mi me afecta porque siento como si no les explicara bien o como si no me entendieran. Se los digo, y al rato ya se les olvidó. Por eso, a veces es más fácil trabajar con máquinas que trabajar con el personal ¿por qué? Pues como se dice cada cabeza es un mundo y a veces no esperas esas reacciones, aunque a veces se va acostumbrando uno. 


\section{ANEXO II}

GRÁFICAS DE LA INDUSTRIA MAQUILADORA OPERANDO EN YUCATÁN

EMPRESAS MAQUILADORAS EN EXPORTACIÓN 100\% EXPORTADORAS

\begin{tabular}{|c|c|c|c|c|}
\hline NOMBre de la EMpresa Maquiladora & UBicaCión & EMPLEADOS & $\begin{array}{l}\text { PROCEDENCIA } \\
\text { DEL CAPITAL }\end{array}$ & RAMA \\
\hline 1.-Plainco Mexicana, S.A. de C.V. & Mérida & 56 & $100 \%$ americano & 2 \\
\hline 3.-Balmex, S, de R.L. de C.V. & Mérida-Progreso & 1007 & $100 \%$ americano & 1 \\
\hline 4.-Stitch World, S.A. de C.V. & Mérida & 65 & $100 \%$ americano & 1 \\
\hline 5.-Cara de México, S.A. de C. V. & Mérida & 119 & $100 \%$ americano & 2 \\
\hline 8.-Diamoro Mex. S.A. de C.V. & Mérida & 425 & $100 \%$ americano & 2 \\
\hline 9.-Viti Fashions American, S.A. de C.V. & Mérida & 267 & $100 \%$ americano & 1 \\
\hline 10.-Dinastía Mexicana, S.A. de C.V. & Mérida-Umán & 483 & $100 \%$ americano & 2 \\
\hline 12.-Fashion Inventory Management, S.A. de C.V & Mérida & 22 & $100 \%$ americano & 1 \\
\hline 13.-Falco Electronics México & Mérida-Umán & 558 & $100 \%$ americano & 4 \\
\hline 15.-Industrias Goldmex. S.A. de C.V. ${ }^{*}$ & Mérida & 23 & $100 \%$ americano & 2 \\
\hline 16.-Industrias Oxford de Mérida, S..A. de C.V. & Mérida-Progreso & 839 & $100 \%$ americano & 1 \\
\hline 17.-Dew Tex, S.A. de C.V. & Mérida & 267 & $100 \%$ americano & 1 \\
\hline 18.-Joyas de Exportación, S.A.de C.V. & Mérida-Umán & 263 & $100 \%$ americano & 2 \\
\hline 19.-Ladcomex. S.A. de C. V. & Mérida & 37 & $100 \%$ americano & 4 \\
\hline 20.-Manotec, S. A. de C.V. & Mérida & 137 & $100 \%$ americano & 2 \\
\hline 22.-Manufacturera Lee de Mexico, S. A. de C.V. & Izamal & 2097 & $100 \%$ americano & 1 \\
\hline $\begin{array}{l}\text { 23.-Manufacturera Lee de Tekax, S. A. de C. V. } \\
\text { 24.-Maquiladora de Contrac Fibberglass }\end{array}$ & Tekax & 650 & $100 \%$ americano & 1 \\
\hline Products, S.A de C.V. ${ }^{*}$ & Mérida & 15 & $100 \%$ americano & 5 \\
\hline 26.-Mérida Data, S.A. de C.V. & Mérida & 64 & $100 \%$ americano & 6 \\
\hline 27.-Ormex, S.A. de C.V. & Mérida-Umán & 600 & $100 \%$ americano & 3 \\
\hline 29.-Quality Textile, S.A. de C. V. & Halacho & 462 & $100 \%$ americano & 1 \\
\hline 30.-R.B. Tex, S.A. de C.V. & Mérida & 297 & $100 \%$ americano & 1 \\
\hline 31.-Reliable American, S.A. de C.V. & Mérida & 87 & $100 \%$ americano & 1 \\
\hline 32.-Reytek, S.A. de C.V. & Mérida & 75 & $100 \%$ americano & 3 \\
\hline 33.-Safegear de México, S.A. de C.V. & Mérida & 520 & $100 \%$ americano & 5 \\
\hline 34.-Sammax International, S.A. de C. V. * & Tecoh & 165 & $100 \%$ americano & 4 \\
\hline 35.-Tiburón de Tierra, S.A. de C.V. & Progreso & 2 & $100 \%$ americano & 7 \\
\hline 36.-Manufacturas Gambella, S.A. de C.V. & Mérida & 67 & $100 \%$ americano & 1 \\
\hline 37.-Vogue Dessous, S. A. de C. V. & Mérida & 502 & $100 \%$ canadiense & 1 \\
\hline 38.-Pescados y Mariscos del Sol, S.A. de C.V. & Conkal-Chablekal & 3 & $100 \%$ canadiense & 7 \\
\hline 39.-Charlotte Apparel, S.A. de C.V. & Mérida & 32 & $100 \%$ china & 1 \\
\hline 40.-Produce México, S. A. de C.V. & Mérida & 392 & $100 \%$ Italiano & 1 \\
\hline 41.-Monty Industries, S.A. de C. V. & Motul & 3.396 & $100 \%$ Hong Kong & 1 \\
\hline 42.-Standard Industries, S.A. de C.V. & Maxcanu & 519 & $100 \%$ hong kong & 1 \\
\hline 43.-Anchor Exportación, S.A. de C.V. & Ixil & 315 & $100 \%$ nacional & 1 \\
\hline 44.-Crisca, S.A. de C.V. & Mérida & 14 & $100 \%$ nacional & 1 \\
\hline 45.-Distribuciones Exclusivas Daale de Yucatán, & & & & \\
\hline S.A. de C.V. & Mérida & 8 & $100 \%$ nacional & 5 \\
\hline 46.-Grupo Brasamex, S.A. de C.V. & Mérida-Progreso & 21 & $100 \%$ nacional & 1 \\
\hline 47.-Tepalil-na, S.A. de C.V. & Motul & 801 & $100 \%$ nacional & 1 \\
\hline 48.-Dionisio Uc Koyoc & Izamal & 5 & $100 \%$ nacional & 4 \\
\hline 49.-Orsenico Rodriguez, S.A. de C.V. & Mérida & 16 & $100 \%$ nacional & 2 \\
\hline
\end{tabular}


BEATRIZ CASTILLA R. - BEATRIZ TORRES G.

\begin{tabular}{|c|c|c|c|c|}
\hline NOMBRE DE la EMPRESA MAQULLADORA & UBicación & EMPLEADOS & $\begin{array}{l}\text { PROCEDENCIA } \\
\text { DEL CAPTTAL }\end{array}$ & RAMA \\
\hline 50.-Carlos Jimenez y Caamal & Mérida & 2 & $100 \%$ nacional & 5 \\
\hline 51.-DD Manufactures, S.A. de C.V. & Mérida & 615 & $100 \%$ nacional & 5 \\
\hline 52.-Originales Tipy, S.A. de C.V. & Mérida & 619 & $100 \%$ nacional & 1 \\
\hline 53.-Yield de México, S.A. de C.V. & Mérida & 57 & $100 \%$ nacional & 1 \\
\hline 55.-Procesadora Mol-ane, S.A. de C.V. & Mérida & 12 & $100 \%$ nacional & 7 \\
\hline 56.-Industrias Rasini, S.A. de C.V. & Mérida & 204 & $100 \%$ nacional & 1 \\
\hline 57.-Industria Textil de Yucatan, S.A. de C.V. & Mérida & 364 & $100 \%$ nacional & 1 \\
\hline 58.-Aleph Fashion Industries, S.A. de C.V. & Mérida & 156 & $100 \%$ nacional & 1 \\
\hline 59.-Joyas de Gingo,S.A. de C.V. & Mérida & 43 & $100 \%$ nacional & 2 \\
\hline 60.-Veltek Industries de Mexico, S.A. de C.V. & Mérida-Progreso & 24 & $100 \%$ nacional & 4 \\
\hline 61.-A \& B Production, S.A. de C.V. & Hunucma & 125 & $100 \%$ nacional & 1 \\
\hline 62.-Unisource 2000 Sportwear, S.A. de C.V. & Mérida & 138 & $\begin{array}{l}20 \% \text { nacional / } \\
80 \% \text { americano }\end{array}$ & 1 \\
\hline 63.-Meritronics, S.A. de C.V. & Mérida & 62 & $\begin{array}{l}20 \% \text { nacional / } \\
80 \% \text { americano }\end{array}$ & 4 \\
\hline 64.-Aluxus 21, S.A. de C.V. & Cholul & 30 & $\begin{array}{l}50 \% \text { nacional / } \\
50 \% \text { americano }\end{array}$ & 5 \\
\hline 65.-Mexgloves, S.A. de C.V. & Mérida & 156 & $\begin{array}{l}51 \% \text { nacional / } \\
49 \% \text { americano }\end{array}$ & 5 \\
\hline 66.-Industria Textil Maya, S.A. de C.V. & Mérida-Umán & 192 & $\begin{array}{l}51 \% \text { nacional / } \\
49 \% \text { panameño }\end{array}$ & 1 \\
\hline 67.-Litehouse, S.A. de C.V. & Mérida-Progreso & 22 & $\begin{array}{l}73.5 \% \text { nacional / } \\
26.5 \text { extranjero }\end{array}$ & 4 \\
\hline 68.-Columbian Rope de México, S.A. de C.V. & Mérida & 12 & $\begin{array}{l}30 \% \text { nacional / } \\
70 \% \text { americano }\end{array}$ & 5 \\
\hline 69.-Mexaisi, S.A. de C.V. & Mérida & 55 & $\begin{array}{l}75 \% \text { chinos / } \\
25 \% \text { americanos }\end{array}$ & 1 \\
\hline 70.-J. A. Chao, S.A. de C.V. & Mérida & 39 & $\begin{array}{l}99 \% \text { americano } \\
\text { y } 1 \% \text { nacional }\end{array}$ & 2 \\
\hline 71.-Doulton de México, S.A. de C.V: & Mérida & 486 & $\begin{array}{l}99.96 \% \text { Hong Kong } \\
00.04 \% \text { nacional }\end{array}$ & 1 \\
\hline $\begin{array}{l}\text { 72. - Confecciones y Diseños Textiles de Yuc., } \\
\text { S.A. de C.V. }\end{array}$ & Mérida & 624 & $\begin{array}{l}99.99 \% \text { Hong Kong } \\
00.01 \% \text { nacional }\end{array}$ & 1 \\
\hline 73.-Creaciones Textiles de Mérida, S.A. de C.V. & Mérida-Progreso & 1889 & $100 \%$ americano & 1 \\
\hline 74.-A.D.C. Industrias, S.A. de C.V. & Mérida & 38 & $100 \%$ americano & 5 \\
\hline 75.-Sajavia Fashion, S.A. de C.V. & Huhi & 0 & $100 \%$ americano & 1 \\
\hline 76.-Advantage Apparel, S.A. de C.V. & Mérida & 83 & $100 \%$ americano & 1 \\
\hline 77.-Dimamex, S.A. de C.V. & Chicxulub Pueblo & 16 & $\%$ nacional / $99 \%$ españ & 5 \\
\hline 78.-Jerzees Yucatán, S.A. de C.V. & Tixkokob & 1276 & $100 \%$ americano & 1 \\
\hline 79.-Hong Ho México, S.A. DE C.V. & Valladolid & 1028 & 100\% Republica China & 1 \\
\hline 80.-Sowat, S.A. De C.V. & Kanasin & 133 & $\begin{array}{l}1 \% \text { nacional / } \\
99 \% \text { americano }\end{array}$ & 1 \\
\hline $\begin{array}{l}\text { 81.-Maquiladora Textil y Serigrafia del Sureste, } \\
\text { S.A. de C.V. }\end{array}$ & Mérida & 22 & & \\
\hline 82.-Forrest de México, S.A. De C.V. & Mérida-Umán & 179 & $100 \%$ americano & 1 \\
\hline 83.-Maxitex, S.A. De C.V. & Mérida-Progreso & 0 & $100 \%$ nacional & 1 \\
\hline 84.-Crown Victoria, S.A. De C.V. & Mérida & 53 & $100 \%$ americano & 1 \\
\hline 85.-Yachts of the Americas, S.A. De C.V. & Mérida-Progreso & 17 & $100 \%$ nacional & 5 \\
\hline 86.-Unique Group de México, S.A. De C.V. & Mérida & 110 & $100 \%$ nacional & 1 \\
\hline 87.-Creaciones Femeninas, S.A. De C.V. & Mérida-Umán & 300 & $100 \%$ americano & 1 \\
\hline
\end{tabular}




\begin{tabular}{|c|c|c|c|c|}
\hline NOMBRE de la EMPRESA MaQULAdORA & UBICACIÓN & EMPLEADOS & $\begin{array}{l}\text { PROCEDEnCIA } \\
\text { DEL CAPITAL }\end{array}$ & RAMA \\
\hline 88.-Ideal Pleating Company, S.A. De C.V. & Mérida & 19 & $100 \%$ americano & 1 \\
\hline 89.-Dunhuang Mex, S.A. De C.V. & Mérida & 22 & $100 \%$ china & 1 \\
\hline 90.-Grupo Harlana, S.A. De C.V. & Mérida & 220 & $100 \%$ americano & 1 \\
\hline 91.-Sahari, S.A. De C.V. & Mérida & 52 & $100 \%$ nacional & 1 \\
\hline 92.-Ree New Fashion, S. De R.L.M.I. & Dzemul & 95 & $100 \%$ nacional & 1 \\
\hline 93.-Bel Manufactures, S.A. De C.V. & Mérida-Progreso & 322 & $100 \%$ nacional & 1 \\
\hline 94.-SRC International S.A. De C.V. & Mérida & 42 & $100 \%$ americano & 2 \\
\hline 95.-RAF Company, S de R.L. De C.V. & Mérida & 220 & $100 \%$ nacional & 4 \\
\hline 96.-Millennium Elastic, S.A. De C.V. & Mérida & 65 & $100 \%$ americano & 5 \\
\hline 97.-J.R.A. Yucatán, S.A. De C.V. & Valladolid & 1700 & $100 \%$ americano & 1 \\
\hline 98.-Kellwood Manufactura, S.A. De C.V. & Motul & 763 & $100 \%$ americano & 1 \\
\hline 99.-Alandem Corporation, S. De R.L. De C.V. & Mérida & 139 & $100 \%$ americano & 1 \\
\hline 100.-Maquiladora Konkal de Exportacion, S.A. De C.V. & Conkal-Chablekal & 186 & $100 \%$ nacional & 1 \\
\hline 101.-Quality Garments de México, S.A. De C.V. & Mérida & 18 & $100 \%$ americano & 1 \\
\hline 102.-Santi Fashion, S.A. De C.V. & Dzidzantun & 106 & $100 \%$ americano & 1 \\
\hline 103.-Limited Cotton, S.A. De C.V. & Mérida & 17 & $100 \%$ nacional & 1 \\
\hline 104.-Millennia Manufacturing, S. De R.L. De C.V. & Mérida-Umán & 600 & $100 \%$ americano & 1 \\
\hline 105.-Industrias Barrotex, S. De R.L. De C.V. & Mérida-Progreso & 154 & $100 \%$ americano & 1 \\
\hline 106.-Yucatán Ventures, S.A. De C.V. & Dzemul & 213 & $65 \%$ americano & 1 \\
\hline $\begin{array}{l}\text { 107.-Industria y Comercio Yalex, S.A. De C.V. } \\
\text { 108.-Apparel Contractors Associates in Yucatán, }\end{array}$ & Mérida-Progreso & 32 & $100 \%$ americano & 1 \\
\hline S.A. de C.V. & Mérida & 243 & $100 \%$ americano & 1 \\
\hline 109.-Eduardo Jose Losa Seijo & Mérida & 25 & $100 \%$ americano & 7 \\
\hline 110.-Manufacturera Lee de Acanceh, S.A. De C.V. & $\begin{array}{l}\text { Acanceh } \\
\text { total de empleados }\end{array}$ & $\begin{array}{r}400 \\
30.527\end{array}$ & $100 \%$ americano & 1 \\
\hline CÓDIGOS PARA EL GIRO & \# DE MAQUIL. $\times$ RAMA & PORCENTAJE & & \\
\hline 1. Textil & 63 & $62,38 \%$ & & \\
\hline 2. Joyería & 11 & $10,89 \%$ & & \\
\hline 3. Aparatos dentales & 2 & $1,98 \%$ & & \\
\hline 4. Equipo electrónico & 8 & $7,92 \%$ & & \\
\hline 5. Otras industrias manufactureras & 12 & $11,88 \%$ & & \\
\hline 6. Servicios & 1 & $0,99 \%$ & & \\
\hline 7. Procesamiento de alimentos & 4 & $3,96 \%$ & & \\
\hline TOTAL DE MAQUILADORAS 100\% EXPORTADORAS & 101 & & & \\
\hline
\end{tabular}

Fuente: A partir de la información proporcionada por SECOFI e información directa. Castilla, Beatriz. Tesis doctoral: Nouvelles technologies et changements culturels chez les ouvrières Mayas travaillant dans une usine de montage au Yucatán. Universidad de Perpignan, Francia (en proceso). 


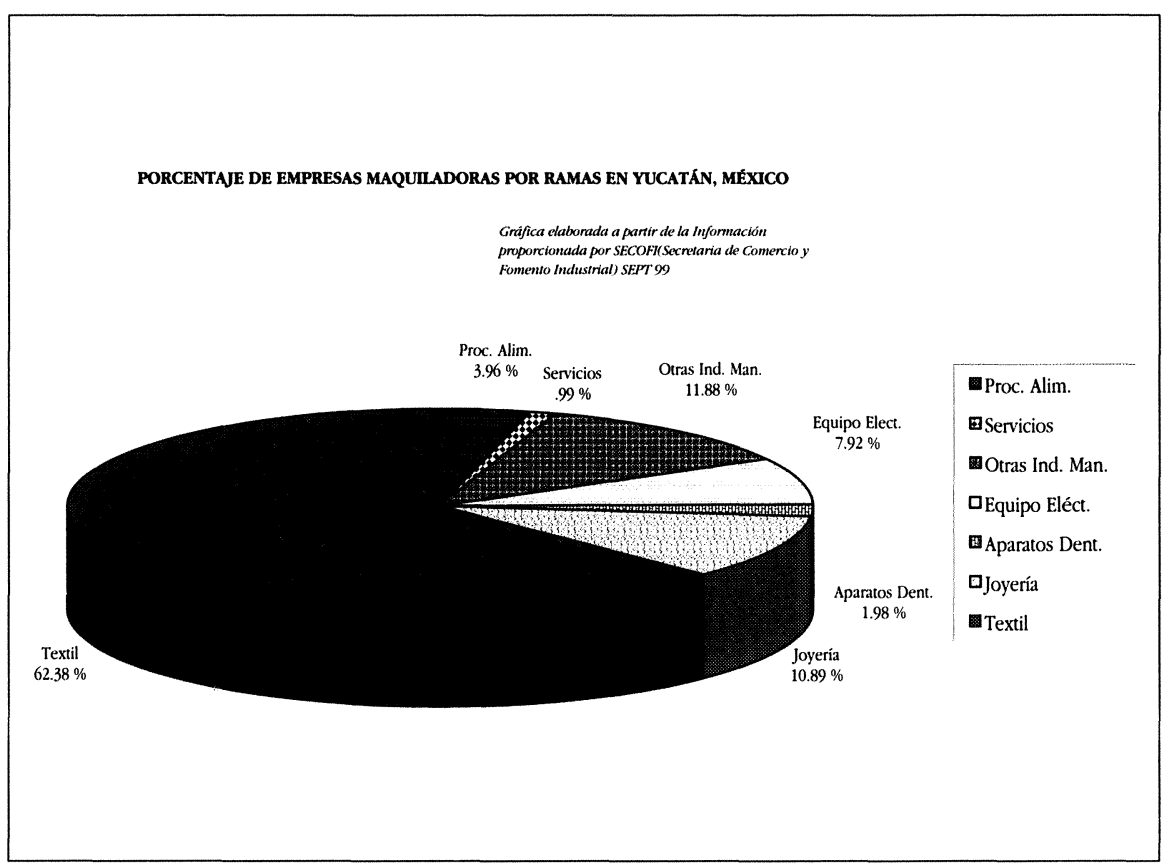

FUENTE: Castilla (2000).

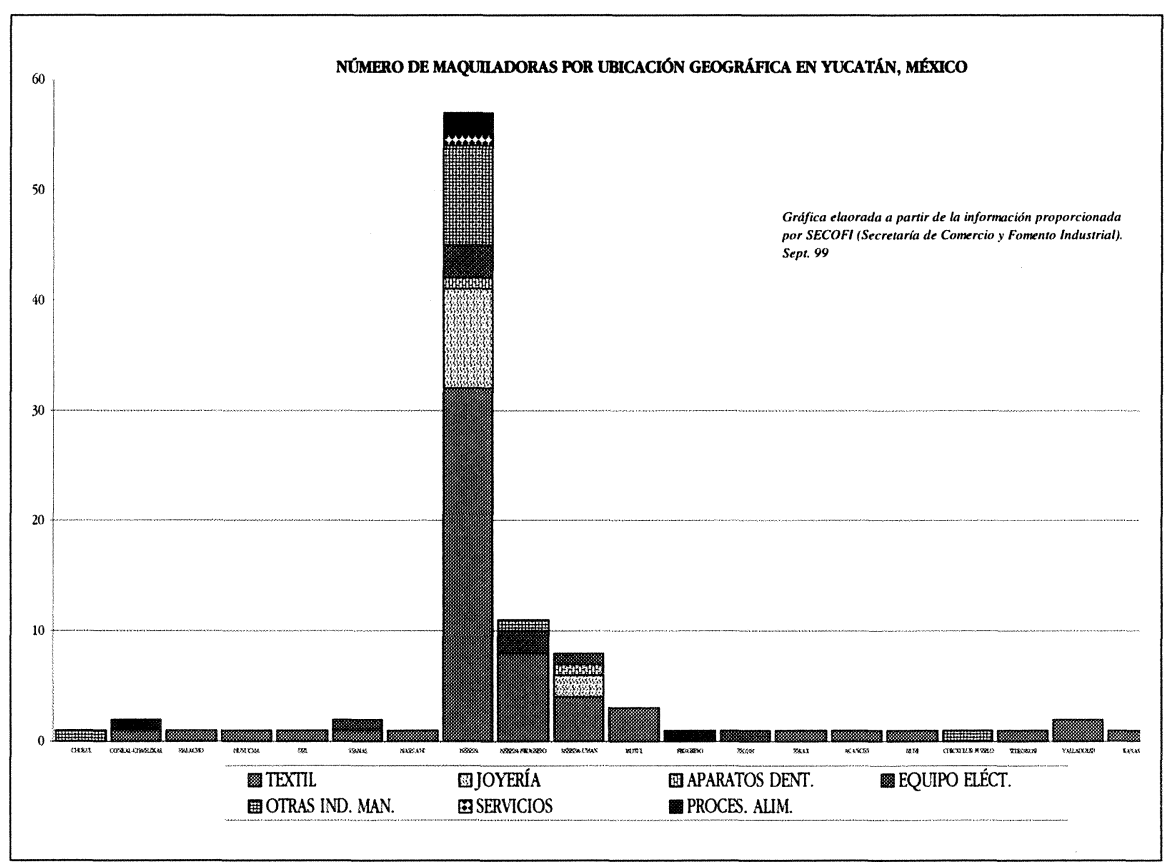

FUENTE: Castilla (2000). 



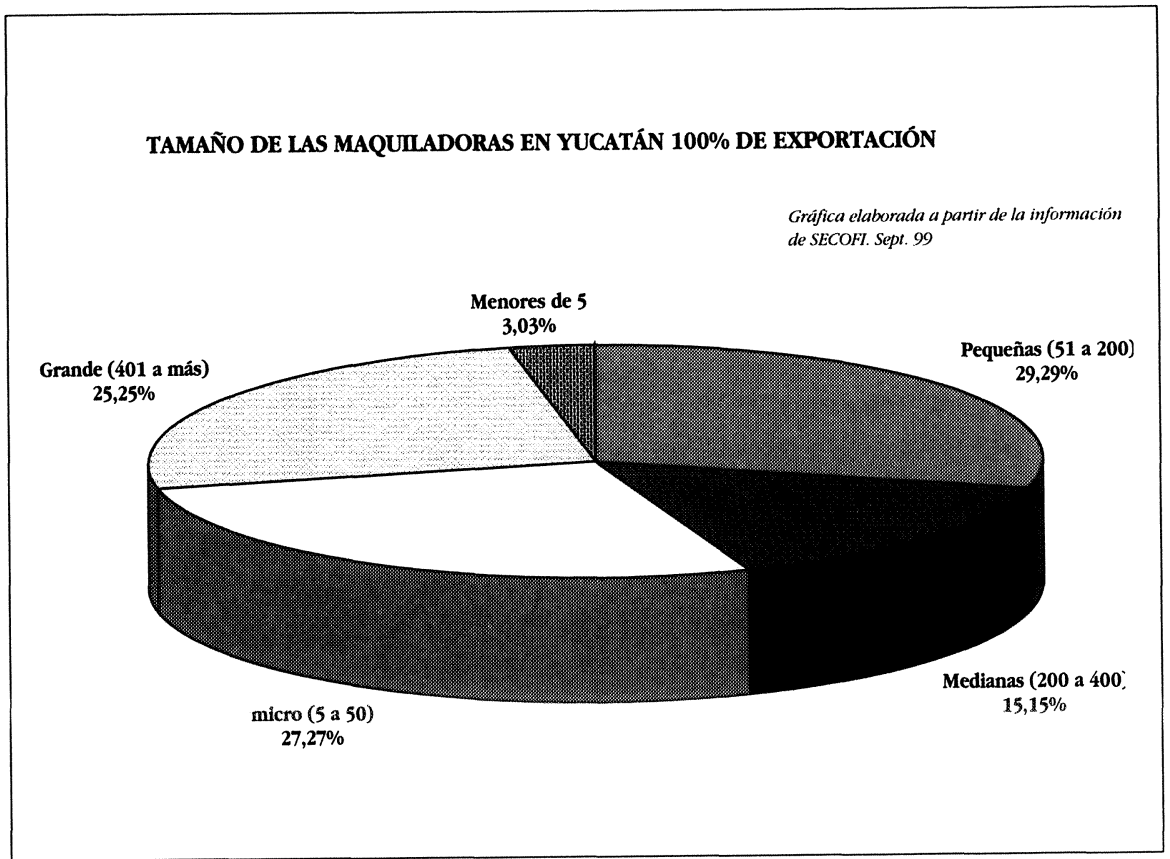

FUENTE: Castilla (2000).

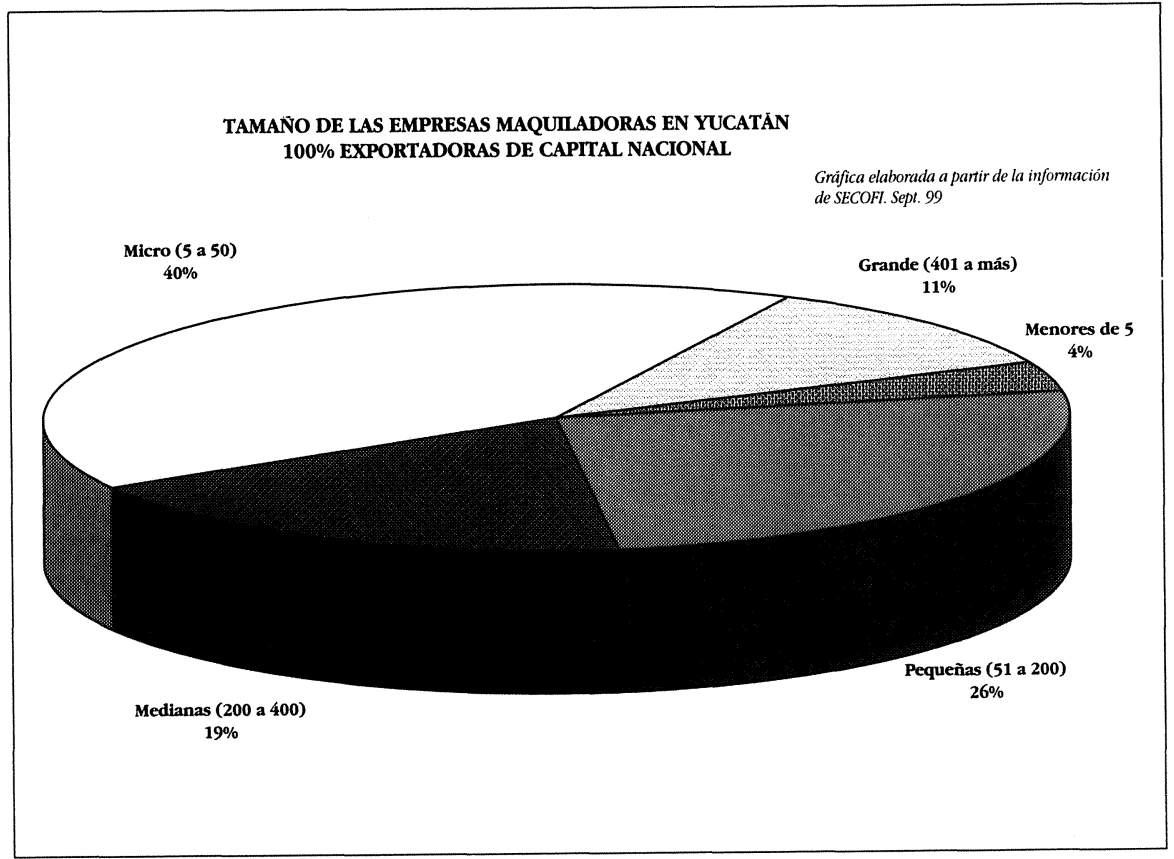

FUENTE: Castilla (2000). 


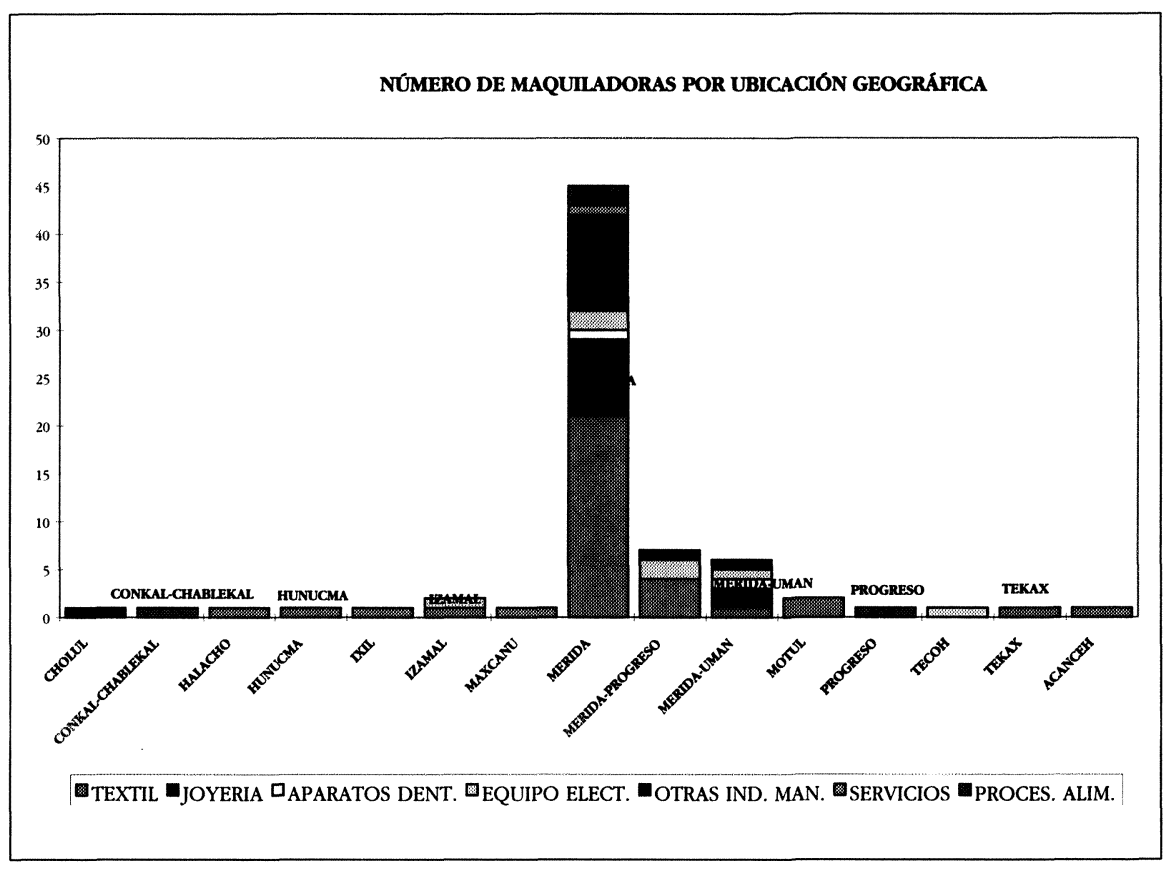

FUENTE: Castilla (2000).

EMPRESAS MAQUILADORAS EN OPERACIÓN DE CAPACIDAD OCIOSA Y CREADAS EX-PROFESO

\begin{tabular}{|c|c|c|c|c|}
\hline NOMBRE DE la EMPRESA MAQUILAdORA & UBicaCión & EMPLEADOS & $\begin{array}{l}\text { PROCEDENCIA } \\
\text { DEL CAPITAL }\end{array}$ & RaMA \\
\hline 1.-Manufacturera de Ropa Meridana, S.A. & Mérida & 125 & $100 \%$ nacional & 1 \\
\hline 2.-Industrias Mayafiel, S.A. de C.V.* & Mérida & 30 & $100 \%$ nacional & 1 \\
\hline 3.-Tejidos de Punto Wabi, S.A. de C.V. & Mérida & 50 & $100 \%$ nacional & 1 \\
\hline 4.-Yucatán Export e Import, S.A. de C.V. & Mérida & 3 & $100 \%$ nacional & 7 \\
\hline 5.-Mayan Produce, S.A. de C.V. & Mérida & 2 & $100 \%$ nacional & 6 \\
\hline 7.-Candila Exportaciones, S.A. de C.V. & Mérida & 75 & $100 \%$ nacional & 1 \\
\hline 8.-Luis Achurra Sucesores, S.A. de C.V. & Mérida-Umán & 49 & $100 \%$ nacional & 5 \\
\hline 9.-Maya Frog, S.A. de C.V. & Tahmek & 20 & $100 \%$ nacional & 7 \\
\hline 10.-Productos Practicos de Madera, S.A. de C.V. & Mérida & 10 & $100 \%$ nacional & 5 \\
\hline 11.-Almacenes el Nilo, S.A. de C.V. & Mérida & 71 & $100 \%$ nacional & 1 \\
\hline 12.-Multibordados de Exportación, S.A. de C.V. & Mérida & 10 & $100 \%$ nacional & 1 \\
\hline 13.-Liborio Koh Torres & Tekit & 11 & $100 \%$ nacional & 1 \\
\hline 14.-Dicasu, S.A. de C.V. & Mérida & 437 & $100 \%$ nacional & 1 \\
\hline 15.-Torrelodones, S.A. de C.V. & Mérida & 40 & $100 \%$ nacional & 5 \\
\hline 16.-Manufacturera Peninsular, S.A. de C.V. & Mérida & 46 & $100 \%$ nacional & 5 \\
\hline 17.-Impulsora Textil del Sureste, S.A. de C.V. & Mérida & 58 & $100 \%$ nacional & 1 \\
\hline 18.-Mukul Koh José Misael & Tekit & 4 & $100 \%$ nacional & 1 \\
\hline 19.-Watex, S.A. de C.V. & Motul-Cholul & 20 & $100 \%$ nacional & 1 \\
\hline 20.-Horizontes Martin, S.A. de C.V. & Mérida & 6 & $100 \%$ nacional & 5 \\
\hline 21.-Luz Hortensia Llamas Monjardin & Mérida & 57 & $100 \%$ nacional & 1 \\
\hline 22.-Coco Frio, S.A. de C.V. & Mérida & 11 & $100 \%$ nacional & 6 \\
\hline
\end{tabular}




\begin{tabular}{|c|c|c|c|c|}
\hline NOMBRE DE LA EMrResa MaQunadora & UBicación & EMPLEADOS & $\begin{array}{l}\text { PROCEDENCIA } \\
\text { DEL CARITAL }\end{array}$ & RAMA \\
\hline 23.-Miriñaques y Bolsas, S.A. de C.V. & Mérida & 11 & $100 \%$ nacional & 5 \\
\hline 24.-Sara Maria Simón Miguel & Mérida & 31 & $100 \%$ nacional & 1 \\
\hline 25.-Impresos Flexibles, S.A. de C.V. & Cholul & 15 & $100 \%$ nacional & 5 \\
\hline 27.-Manufacturas Finas Ravgo, S.A. de C.V. & Mérida & 61 & $100 \%$ nacional & 1 \\
\hline 28.-Cosmopolitan Marketing Corporation, S.A. de C.V. & Mérida & 657 & $100 \%$ nacional & 1 \\
\hline 29.-Saxón de Yucatán, S.A. de C.V. & Mérida-Umán & 74 & $62 \%$ nacional $/ 38 \%$ americano & 5 \\
\hline 30.-Neri Consuelo Teresita Erosa Lizarraga & Mérida & 12 & $5 \%$ nacional $/ 95 \%$ americano & 5 \\
\hline 31.-Derivados de Henequen del Mayab, S.A. de C.V. & Mérida & 113 & $50 \%$ nacional/50\% americano & 5 \\
\hline 32.-DRS Ceramica, S.A. De C.V. & Mérida & 0 & $100 \%$ americano & 5 \\
\hline 33.-Cia. Manufacturera del Sureste, S. De R.L. De C.V & Tekit & 0 & $100 \%$ nacional & 1 \\
\hline 34.-Boneteria Wabi, S.A. De C.V. & Mérida & 118 & $100 \%$ nacional & 1 \\
\hline 35.-Penco de México, S.A. De C.V. & Mérida-Umán & 594 & $100 \%$ Hong Kong & 1 \\
\hline 36.-Desarrollo Exportador Textil, S.A. De C.V. & Dzitya & 178 & $100 \%$ nacional & 1 \\
\hline 37.-Tecno Cristal Millet, S.A. De C.V. & Mérida & 10 & $100 \%$ nacional & 6 \\
\hline 38.-Originales Ashanty, S.A. De C.V. & Mérida & 29 & $100 \%$ nacional & 1 \\
\hline 39.-Ellie Manufacturing, S.A. De C.V. & Mérida & 0 & $100 \%$ americano & 1 \\
\hline 40.-Eagle Industries, S.A. De C.V. & Maxcanu & 579 & $100 \%$ americano & 1 \\
\hline 41--Anyali, S.A. De C.V. & Mérida & 132 & $100 \%$ americano & 1 \\
\hline 42.-Matex de Mérida, S.A. De C.V. & Mérida & 78 & $100 \%$ nacional & 1 \\
\hline 43.-Stahlsac de Mérida, S.A. De C.V. & Mérida & 58 & $100 \%$ americano & 1 \\
\hline 44.-Fansa, S.A. De C.V. & Mérida & 14 & $100 \%$ nacional & 4 \\
\hline 45.-Mayafiel International, S.A. De C.V. & Mérida & 90 & $100 \%$ americano & 1 \\
\hline 46.-Perfiles Cominssa, S.A. De C.V. & $\begin{array}{l}\text { Mérida-Umán } \\
\text { total de empleos }\end{array}$ & $\begin{array}{r}11 \\
4000\end{array}$ & $100 \%$ americano & 5 \\
\hline
\end{tabular}

Fuente: A partir de la información proporcionada por SECOFI e información directa.

Castilla, Beatriz. Tesis doctoral: Nouvelles technologies et changement culturels chez les ouvrières Mayas travaillant dans une usine de montage au Yucatàn. Universidad de Perpignan, Francia (en proceso).

\section{EMPRESAS MAQUILADORAS DE CAPACIDAD OCIOSA POR RAMAS EN YUCATÁN, MÉXICO}

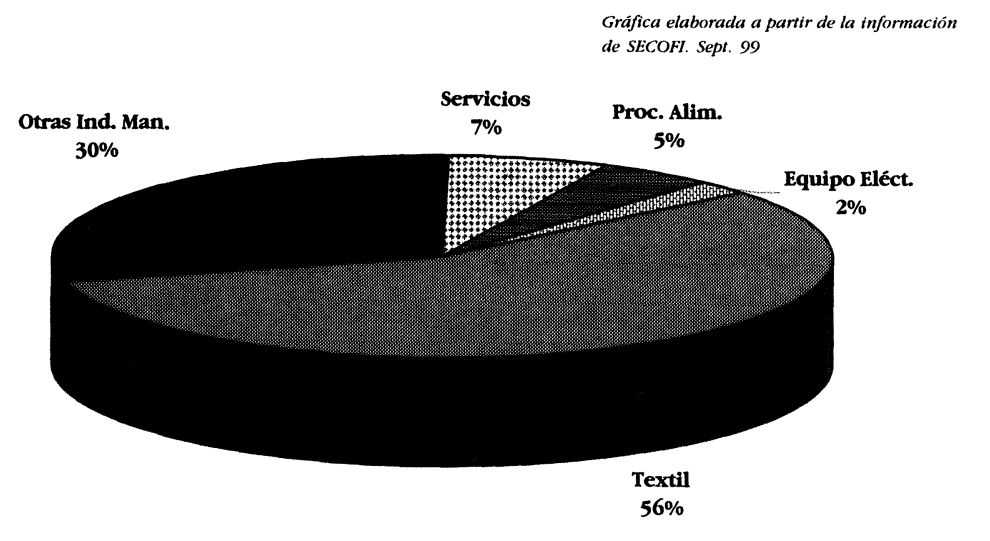

FuENTE: Castilla (2000). 


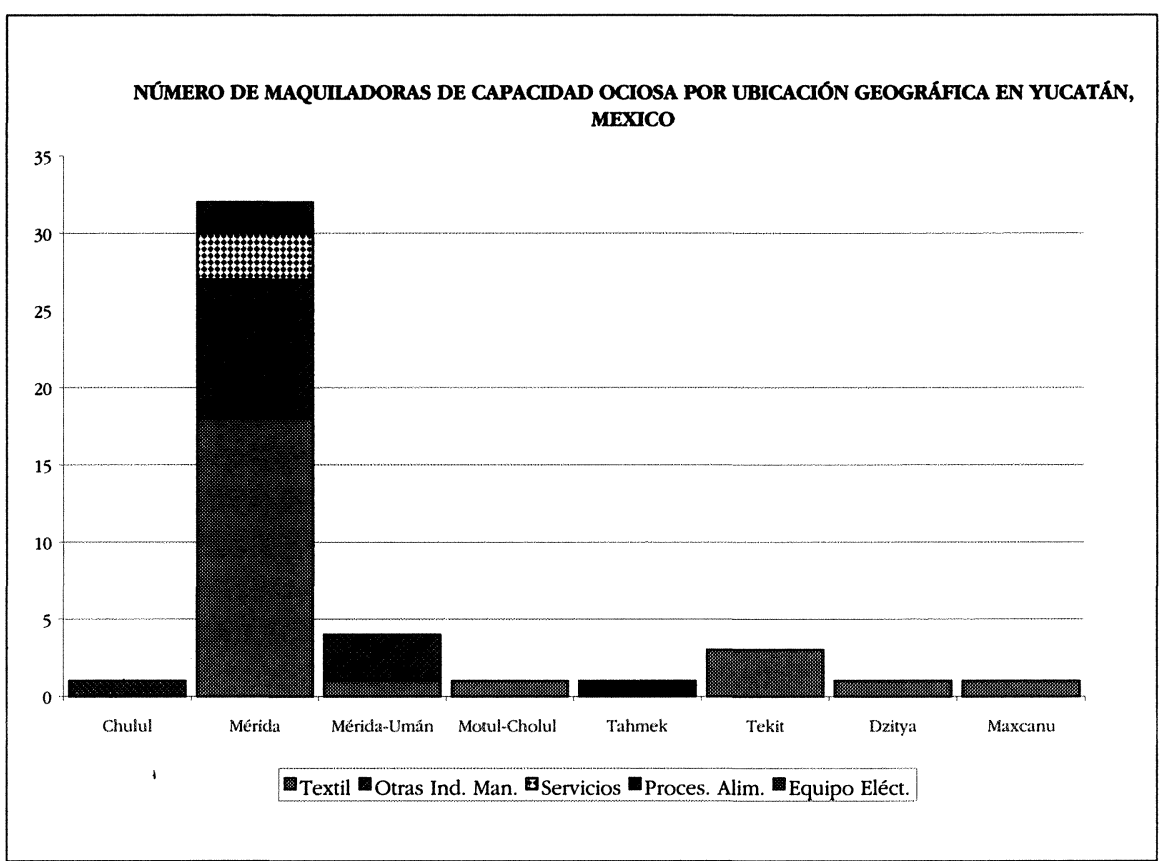

FUENTE: Castilla (2000).

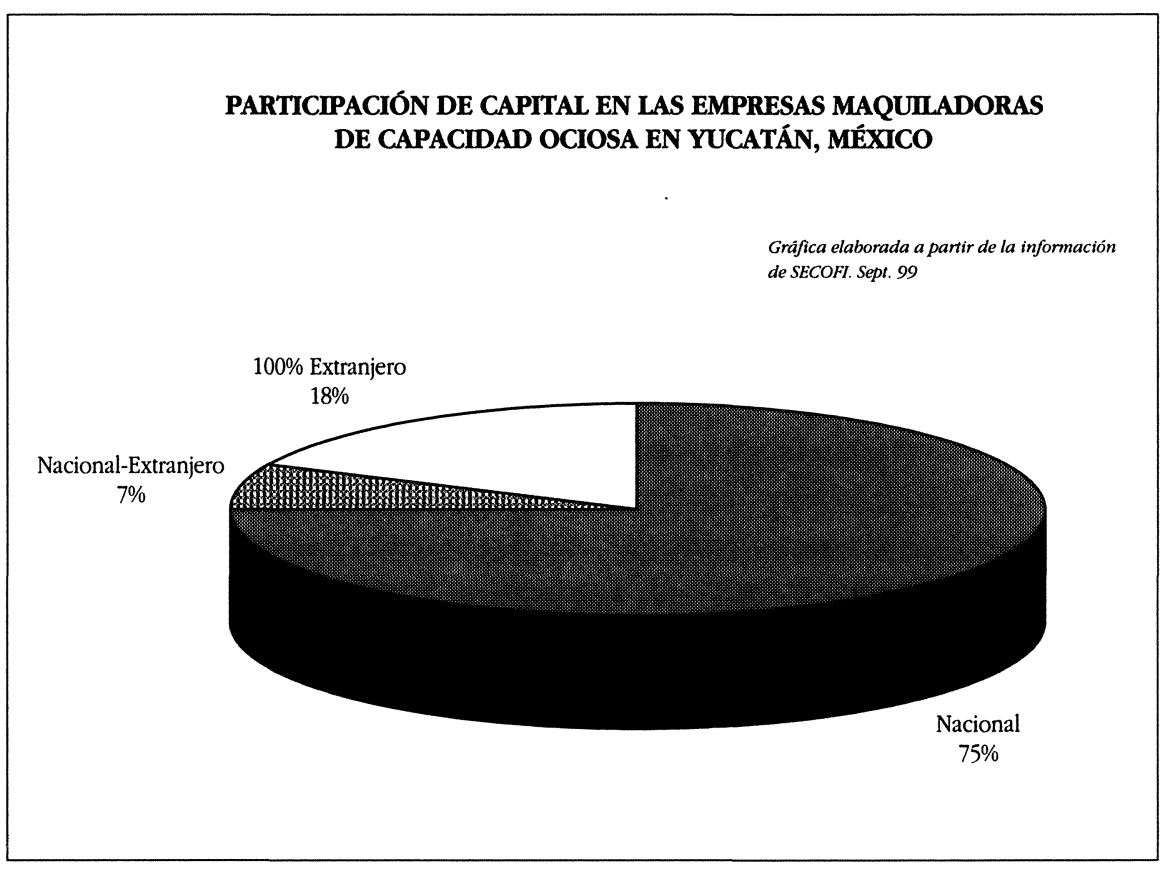

FUENTE: Castilla (2000). 


\section{BIBLIOGRAFÍA CITADA}

Aво, Т. et al. 1989. Japanese and European Management. Their International Adaptability. Tokyo: University of Tokyo Press.

ALBORNOZ, L. 2000. Maquiladoras: nueva estrategia de desarrollo rural. Tesis de Licenciatura en Economía, Facultad de Economía, UADY, Mérida, Yuc.

ARTEAGA, A. 2000. "Cambios en la Organización de la Producción", en Perspectivas del Mercado de Trabajo en México. Seminario de Investigación Laboral. Secretaría del Trabajo: México, D.F.

BiLBAO, A. 1999. "Modelo liberal y reorganización de las relaciones laborales". Perfiles de Población 5 (20).

CARRILLO, J. 1998. Seminario de Investigación sobre la Industria Maquiladora en México. Unidad de Ciencias Sociales, CIR. UADY. Mérida, Yucatán, México. Septiembre de 1998.

CARrillo, J. y O. Contreras. 1992. “Calificación en el Trabajo: Análisis de la Industria Maquiladora.". Frontera Norte, El Colegio de la Frontera Norte, Tijuana.

CARRILlO, J. y M. E. DE LA O. 1991. "La Reestructuración en la Industria Maquiladora". El Cotidiano Revista de la realidad mexicana actual 7 (46).

CASTilla Ramos, B. 2000. “Trabajo Fabril y Comunidad: Un acercamiento de análisis del consenso en una maquiladora estadounidense en Yucatán México", en Coloquio Internacional. Integración económica, y desarrollo empresarial. Montpellier, Graduate School of Management. Ecole Supérieure du Commerce.

- en proceso. Nouvelles technologies et changements culturels chez les ouvrières mayas travaillant dans une usine de montage americaine au Yucatán, Mexique. Universidad de Perpignan. Tesis Doctoral en Sociología en proceso.

CASTILlA, B. y B. TORRES. 1994a. "Algunas Transformaciones del Sector Maquilador Yucateco". El Cotidiano.

- 1994b. "Un nuevo impulso a la industria maquiladora", en J. L. Sierra Villareal y J. de J. Huchim Koyoc (comps.), Yucatán de Cara al Siglo XXI. Mérida: Compañía Editorial de la Península.

- 1997. Modelos de Industrialización en Mérida: zona Mérida. Informe de Investigación UCS-CIR-UADY.

Castilla, B. et al. 1997. ¿Quiénes son las trabajadoras de Ormex? Documento interno de la empresa.

- 1997. Dos tiempos, dos mundos. El Santo Cristo del Amor. Mérida, Yucatán, México (videodocumental).

- 1989. "Tendencias y nuevas condiciones de incorporación femenina en la actividad económica yucateca", Fuerza de trabajo femenina urbana en México. México D.F.: Ediciones Porrúa y Coordinación de Humanidades. Vol. I.

- 2000. Las que Cruzaron El Puente: Trabajo Fabril y Comunidad. Mérida, Yucatán, México (videodocumental).

Commailles, J. 1993. Les Strategies des Femmes. Travail et Politique. Paris: Editions la Découverte.

DE LA GARZA, E. et al. 1998. "Modelos de Industrialización en México”. Cuadernos del Trabajo 15.

DE la GaRzA, E. y M. CAMPILLO. 1998. "Hacía dónde va el trabajo humano" Revista Trabajo, segunda época, 1 (1). 
García QuintanIlla, A. 1982. "En busca de una voz". Yucatán, Historia y Economía Revista de DEES CIR-UADY 30.

- 1999. Zaatal: cuando los milperos perdieron el alma. Una bistoria de los mayas, Yucatán, 1880-1889. Tesis Doctoral, Universidad de Carolina del Norte.

García, A. y B. Castilla, 1982. "Mujeres, Telares, y Patíes, en el Yucatán Colonial". Yucatán, Historia y Economía. Revista de DEES CIR-UADY 30.

HuAlDE, A. y A. MERCADO. 1996. "Al Sur de California, Industrialización sin Empresarios". Revista Latinoamericana de Estudios del Trabajo 2 (3).

LAHERA, A. 1998. "Fábrica y Comunidad". Sociología del Trabajo 33.

LINHART, D. 1997. "El trabaj() y el empleo en Francia: algunos elementos del debate científicon. Sociología del Trabajo 31.

MilkmaN, R. 1997. "El nuevo trabajo americano ¿buen camino o mal camino?". Sociología del Trabajo 31.

PAlENZUElA, P. 1995. "La cultura del trabajo: una aproximación antropológica". Sociología del Trabajo 24.

Pavageau, J. 1994. "Contribution a la Sociologie de L'Emergence", en Des hommes, leurs espaces, et leurs aspirations: Homage a P. H. Chombart de Lauwe. Paris: L'Harmattan.

Pavageau, J. y P. Schaffhauser. 1995. Mexique-Californie. Mobilité des biens transformation de la vie sociale au Mexique. Perpignan: Centre de Recherches Ibériques et Latino-Americaines. Presses Universitaires de Perpignan.

OPALín, L. 1995. "Repunte de la Industria Maquiladora". El Financiero.

RAMíreZ, L. 1997. Secretos de familia. Libaneses y élites empresariales en Yucatán. México: Conaculta.

REYGADAS, L. 1998. "La dimensión desconocida: el mundo simbólico del trabajo", en M. E. de la $\mathrm{O}$ et al., Los estudios sobre la cultura obrera en México. Culturas populares. México D.F.: UAM-Iztapalapa.

TORRES, B. 1987. Integración de la mujer a la actividad económica de Yucatán. Tesis de Licenciatura en Economía. Facultad de Economía, UADY, Mérida, Yucatán.

- 1998. "Importante presencia de las mujeres en Yucatán; evolución del trabajo femenino remunerado en el Estado. 1885-1890". Pulso Económico. Revista del Colegio de Economistas de Yucatán A.C. 3 (9-10).

- en proceso. Modernización productiva, sistemas de trabajo y recursos bumanos en la industria de Alimentos y Bebidas de Yucatán. Tesis Doctoral en Estudios Laborales. UAM-IZT, México, D.F.

VAlEnzuela, P. 1995. "La Cultura del Trabajo: una aproximación antropológica". Sociología del Trabajo 24.

VILlamil, J. 1997. "Maquiladoras, del Oro Verde al Oro Fabril". Tiempo Económico. Revista de Análisis Socioeconómico Regional 1.

YoshiHARA, H. 1989. "The Bright and the Dark Sides of japanese Management Overseas", en K. Shibagaki, T. Abo, et al. Japanese and European Management. Their International Adaptability. Tokyo: University of Tokyo Press. 